\begin{tabular}{|c|l|}
\hline Title & Modeling low-level clouds over the Okhotsk Sea in summer: Cloud formation and its effects on the Okhotsk high \\
\hline Author(s) & Koseki, Shunya; Nakamura, Tomohiro; Mitsudera, Humio; W ang, Y uqing \\
\hline Citation & $\begin{array}{l}\text { Journal of Geophysical Research, A tmospheres, 117(D5), D05208 } \\
\text { https://doi.org/10.1029/2011D016462 }\end{array}$ \\
\hline Issue Date & 2012-03 \\
\hline Doc URL & http://hdl.handle.net/2115/51237 \\
\hline Rights & Copyright 2012 by the A merican Geophysical Union. \\
\hline Type & article \\
\hline File Information & jgrd17499.pdf \\
\hline
\end{tabular}

Instructions for use 


\title{
Modeling low-level clouds over the Okhotsk Sea in summer: Cloud formation and its effects on the Okhotsk high
}

\author{
Shunya Koseki, ${ }^{1,2}$ Tomohiro Nakamura, ${ }^{1}$ Humio Mitsudera, ${ }^{1}$ and Yuqing Wang ${ }^{3}$ \\ Received 24 June 2011; revised 27 December 2011; accepted 20 January 2012; published 10 March 2012.
}

[1] In summer the Okhotsk Sea is often covered by low-level clouds, which occasionally co-occur with the Okhotsk high. We investigate the formation of low-level clouds and their effects on the Okhotsk high in July using reanalysis, satellite data, and a regional climate model. Statistical analysis suggests that the amount of low-level clouds over the Okhotsk Sea has a positive relationship with the strength of the Okhotsk high; however, the formation processes of the Okhotsk high and low-level clouds are not dependent on each other. A simulation focusing on July 2003, when the Okhotsk high was the strongest in the past decade, showed low-level cloud formation and resulting strong cooling over most of the Okhotsk Sea, which can be attributed to longwave radiation. Sensitivity experiments with reduced cloud amounts reveal that this radiative flux results in the cooling of the cloud top boundary layer (CBL), thereby reinforcing the Okhotsk high within the CBL. Trajectory analyses show that unsaturated air reaches saturation mainly because of the downward sensible heat flux. After cloud formation, radiative cooling causes an upward sensible heat flux below the clouds. Such cooling and heating roughly balance with the cooling due to evaporation of drizzle and cloud water and the heating due to condensation. Eventually, the CBL achieves a low-temperature steady state over the Okhotsk Sea. Although the latent heat flux is positive over the Okhotsk Sea irrespective of the presence or absence of low-level clouds, associated moisture flux is insignificant for achieving saturation. This positive latent heat flux is enhanced under cloudy conditions and compensates for the loss of water vapor due to condensation.

Citation: Koseki, S., T. Nakamura, H. Mitsudera, and Y. Wang (2012), Modeling low-level clouds over the Okhotsk Sea in summer: Cloud formation and its effects on the Okhotsk high, J. Geophys. Res., 117, D05208, doi:10.1029/2011JD016462.

\section{Introduction}

[2] In summer, the climate over the Okhotsk Sea (Figure 1a) is characterized by the formation of low-level clouds (Figure 1b) and the occurrence of the Okhotsk high, which are considered to be caused by low sea surface temperature (SST; see Figure 1c).

[3] In situ observations and satellite measurements have shown that the Okhotsk Sea is covered by low-level clouds in summer [e.g., Wang, 1985]. Marine low-level clouds frequently form in several cool ocean regions such as the Arctic Ocean [Curry, 1986; Dong and Mace, 2003; Sedlar and Tjernström, 2009], the California Current in the eastern North Pacific Ocean [Paluch and Lenschow, 1991;

\footnotetext{
${ }^{1}$ Pan-Okhotsk Research Center, Institute of Low Temperature Science, Hokkaido University, Sapporo, Japan.

${ }^{2}$ Now at Temasek Laboratories, Nanyang Technological University, Singapore, Singapore.

${ }^{3}$ International Pacific Research Center, School of Ocean and Earth Science and Technology, University of Hawaii at Mānoa, Honolulu, Hawaii, USA.

Copyright 2012 by the American Geophysical Union. 0148-0227/12/2011JD016462
}

Koračin et al., 2005; Lin et al., 2009], and the subarctic Pacific Ocean [Norris et al., 1998; Lewis et al., 2004] in the Northern Hemisphere. These low-level clouds play important roles in the atmosphere and ocean climate through radiative forcing such as radiative cooling at the cloud top and shielding of the solar radiation.

[4] The low-level clouds over the Okhotsk Sea co-occur with the Okhotsk high over nearly the same area. In other regions, such as the Pacific Ocean, they form near the edges of anticyclones rather than over the whole region of anticyclones. The co-occurrence of low-level clouds and the Okhotsk high suggests a relationship between these two processes. Tachibana et al. [2008] used in situ observational data to show the characteristic structure of a cloudy/cloudless atmospheric boundary layer and the difference in the sea surface heat flux in the presence/absence of low-level clouds over the Okhotsk Sea. Kato [1985] suggested that radiative cooling at the tops of low-level clouds is responsible for forming a near-surface cold thin layer over the Okhotsk Sea.

[5] The Okhotsk high is accompanied by a cold layer in the lower troposphere [Ninomiya and Mizuno, 1985] and is responsible for an anomalously cold and humid summer in the northern part of Japan attributed to associated cold 

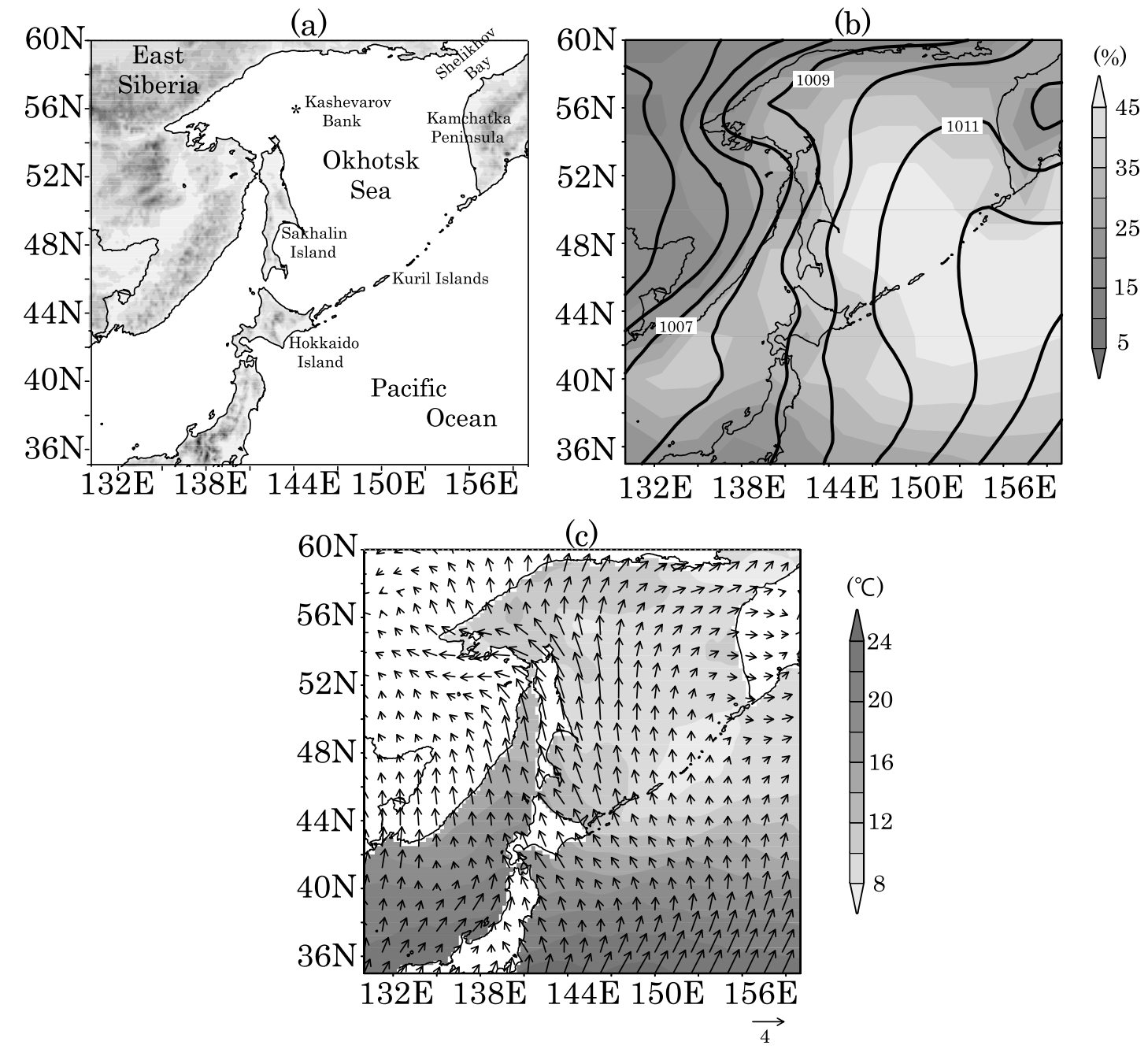

Figure 1. (a) Map around the Okhotsk Sea with topography from ETOPO2 (Earth Topography Two Minute Gridded Elevation data set). (b) Climatology of low-level cloud amount (shading) and sea level pressure (contours) in July. Low-level cloud data (1983-2006) are obtained from the International Satellite Cloud Climatology Project (ISCCP) product, in low-level clouds defined as clouds between 1000 and $680 \mathrm{hPa}$. Sea level pressure data (1980-2007) are from Japanese 25 Year Reanalysis (JRA25) and JMA Climate Data Assimilation System (JCDAS). The horizontal resolutions are $2.5^{\circ} \times 2.5^{\circ}$ (ISCCP) and $1.25^{\circ} \times 1.25^{\circ}$ (for JRA25 and JCDAS). (c) Climatology of horizontal wind at $1000 \mathrm{hPa}(1980-2007$, vectors) from JRA25 and JCDAS and sea surface temperature (1990-2009, shading) from NOAA optimum interpolation sea surface temperature (OISST).

northeasterly winds. These cold winds, known as Yamase winds, cause considerable damage to agriculture in northern Japan [Kodama, 1997; Nagasawa et al., 2006; Takai et al., 2006; Kodama et al., 2009]. The formation mechanism of the Okhotsk high has been revealed in recent years. Tachibana et al. [2004] found a strong correlation between the strength of the Okhotsk high and the meridional temperature gradient at $1000 \mathrm{hPa}$ between the Okhotsk Sea and Siberia. They also showed that the Okhotsk high occurs with two types of vertical structure: one is significant only in the lower troposphere, and the other extends throughout the troposphere. The former type is strongly related to variations in the tropical Pacific Ocean, and the associated air-sea interaction over the Okhotsk Sea is strong. The latter type is linked with variations in the Arctic Ocean, and the air-sea interaction is weak. Nakamura and Fukamachi [2004] concluded that the occurrence of the lower part of Okhotsk high is attributed to the low-level cold surge that accompanies the upper level blocking high, which is usually located to the north of the Okhotsk Sea. Because many of Okhotsk highs are shallow, it is expected that radiative heating due to low-level clouds affects the Okhotsk high, particularly near the surface. Thus, an exploration of the effects of low-level clouds on the Okhotsk high is important for understanding the regional climate over the Okhotsk Sea.

[6] However, the process by which unsaturated air masses achieve saturation to form low-level clouds over the Okhotsk Sea remains a mystery. The low-level clouds over the Okhotsk Sea are dominant near the surface (up to a few hundred meters). This differs greatly from the height of lowlevel clouds over subtropical regions, where these clouds normally reach an altitude of up to $1 \mathrm{~km}$ [Zuidema et al., 
2009]. Klein and Hartmann [1993] have shown that the occurrence of low-level clouds over the North Pacific Ocean is strongly related to the stability between the surface and $700 \mathrm{hPa}$. Over the Yellow Sea, the difference between SST and surface air temperature is an indicator of sea fog formation [Gao et al., 2007; Zhang et al., 2009]. Because lowlevel clouds over the Okhotsk Sea are dominant near the surface, the cloud formation is expected to be related to sea surface flux rather than low-level stability. Koračin et al. [2005] demonstrated through backward trajectory analysis that radiative cooling is responsible for the formation and maintenance of low-level clouds over the California Current. To understand the mechanism of cloud formation over the Okhotsk Sea, the conditions favorable and unfavorable for the low-level cloud formation must be investigated.

[7] In this study, we investigate the cloud formation process over the Okhotsk Sea in summer and the effects of lowlevel clouds on the atmospheric fields over the Okhotsk Sea. In addition to observation and reanalysis data, we use a regional climate model that reproduces low-level clouds quite realistically over the Okhotsk Sea; this is in sharp contrast to many atmospheric general circulation models (AGCMs) that often fail to accurately represent low-level clouds. Because it is difficult to classify low-level clouds and sea fogs in this model, we hereafter regard cloud water and ice near the surface as low-level clouds. Norris and Klein [2000] also investigated low-level clouds over the North Pacific Ocean by categorizing sea fog with low-level clouds. In section 2, we describe the data and model used in this study. Section 3 examines reanalysis and satellite data sets to investigate the relationship between Okhotsk high activity and atmospheric fields. Section 4 shows the results of numerical simulations and the effects of low-level clouds on the atmospheric fields over the Okhotsk Sea. Section 5 describes the cloud formation process by Eulerian and Lagrangian methods. The results are summarized and discussed in section 6 .

\section{Data and Numerical Model}

[8] The data sets used in this study include the Japanese 25 Year Reanalysis (JRA25, from 1979 to 2004) data, Japan Meteorological Agency (JMA) Climate Data Assimilation System (JCDAS, from 2005 to 2006) [Onogi et al., 2007], the low-level cloud data obtained from the International Satellite Cloud Climatology Project product (ISCCP, from 1983 to 2006), and vertically integrated cloud water based on Special Sensor Microwave/Imager (SSMI, 2003). The horizontal resolutions of these data sets are $1.25^{\circ} \times 1.25^{\circ}$ (JRA and JCDAS), $2.5^{\circ} \times 2.5^{\circ}\left(\right.$ ISCCP), and $0.25^{\circ} \times 0.25^{\circ}$ (SSMI). Low-level clouds in the ISCCP are defined as those between 1000 and $680 \mathrm{hPa}$.

[9] We use the International Pacific Research Center, University of Hawaii, regional climate model (IPRCRegCM, now referred to as iRAM) documented in the work of Wang et al. [2003], which is able to reproduce low-level clouds over subtropical oceans [Wang et al., 2004a, 2004b, 2005]. Because the observations of rainfall over the Okhotsk Sea are very limited, we compare the vertically accumulated cloud water data of SSMI and iRAM. The horizontal resolution is set to be $0.5^{\circ} \times 0.5^{\circ}$. This model has 28 levels in the vertical with $\sigma$ as the vertical coordinate; pressure at the top level is $100 \mathrm{hPa}$. Ten of these 28 levels are concentrated below $\sigma_{0.8}$. (Hereafter, $\sigma_{A}$ denotes $\sigma$ corresponding to $A$.) This model includes physical parameterizations for radiation [Edwards and Slingo, 1996; Chou et al., 1998], cumulus convection [Tiedtke, 1989; Nordeng, 1995], turbulence vertical mixing [Detering and Etting, 1985], and cloud microphysics [Wang, 2001]. The cloud microphysics consists of six hydrometeors: rain, cloud liquid water, cloud ice, snow, graupel, and water vapor. This model also includes a land surface scheme known as the Biosphere-Atmosphere Transfer Scheme (BATS) [Dickinson et al., 1993]. For more details, we refer to Wang [2001] and Wang et al. [2003, 2004a, 2007]. Details of the experimental design are described in sections 4 and 5 .

\section{Correlation With Okhotsk High Index}

[10] In this section, we investigate the atmospheric fields associated with the Okhotsk high activity using reanalysis and satellite data. Figure 2a shows the monthly mean Okhotsk high index (OKH index) in July from 1979 to 2006. $\mathrm{OKH}$ index is defined as the area-averaged sea level pressure (SLP) over the Okhotsk Sea, $50^{\circ}-60^{\circ} \mathrm{N}$ and $140^{\circ}-$ $160^{\circ} \mathrm{E}$ [Ogi et al., 2004]. The Okhotsk high activity varies annually, and its index was high in 1988, 1993, 1998, and 2003. These 4 years are widely regarded as the years of cold summers in northern Japan, which were caused by Yamase winds associated with strong Okhotsk high [Kodama, 1997].

[11] Figures $2 b$ and $2 c$ show the correlation of the July mean $1000 \mathrm{hPa}$ horizontal wind and temperature of JRA25, respectively, with the $\mathrm{OKH}$ index. The zonal and meridional components of the vectors shown in Figure $2 b$ are the correlations of zonal and meridional winds with the $\mathrm{OKH}$ index, respectively. When the OKH index is high, anomalous clockwise winds are generated around the Okhotsk Sea, and the anomalous strong northeasterly reaches northern Japan; the clockwise winds and the strong northeasterly correspond to the winds associated with the Okhotsk highs and Yamase winds, respectively. A strong negative correlation of $1000 \mathrm{hPa}$ temperature with the $\mathrm{OKH}$ index is detected in northern Japan and over the Okhotsk Sea. Northern Japan becomes colder when the Okhotsk highs develop, as the Yamase winds bring cold air from the northeast to northern Japan.

[12] Figure 2d illustrates the correlation of the July mean low-level cloud amount from ISCCP with the OKH index. A significant positive correlation is detected over the Okhotsk Sea $\left(45^{\circ}-57^{\circ} \mathrm{N}\right.$ and $\left.138^{\circ}-153^{\circ} \mathrm{E}\right)$. Low-level clouds tend to form more frequently when the Okhotsk high is strong. In contrast, the upper level clouds show a negative correlation with the low-level clouds and the OKH index (not shown); that is, the upper level clouds form less frequently when the Okhotsk high is strong. Because the Okhotsk high is induced by an upper level blocking high, the formation of upper level clouds may be related to the blocking high or atmospheric fields at upper levels.

[13] This statistical analysis reveals a positive correlation between the occurrence of the low-level clouds and the Okhotsk high activity over the Okhotsk Sea on an interannual scale. This significant statistical relationship suggests the co-occurrence of low-level clouds and the Okhotsk high in addition to possible physical connections, such as those 


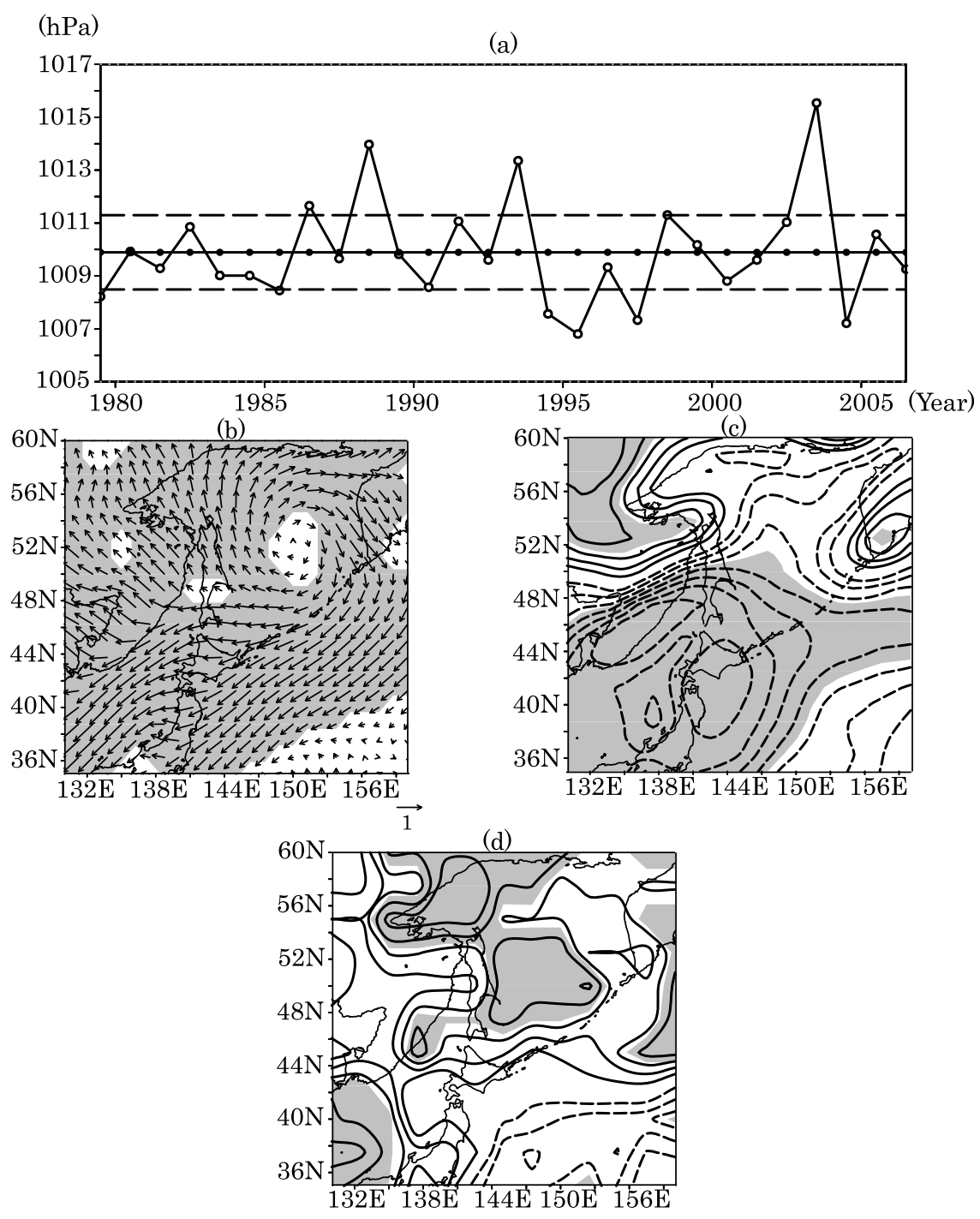

Figure 2. (a) July mean Okhotsk high $(\mathrm{OKH})$ index (area-averaged SLP over $50^{\circ}-60^{\circ} \mathrm{N}$ and $140^{\circ}-$ $160^{\circ} \mathrm{E}$ ) from 1979 to 2006 based on JRA25 and JCDAS (open circle). The temporal mean (solid circle) and \pm 1 standard deviation (dashed line) of the OKH index are shown together. Also shown are correlation maps of (b) $1000 \mathrm{hPa}$ horizontal wind (JRA25 and JCDAS), (c) $1000 \mathrm{hPa}$ temperature (JRA25 and JCDAS), and (d) low-level cloud amount (ISCCP) with the OKH index. Shading is applied where the correlation is significant at the significant level of $95 \%$. In Figure $2 b$ the significance level is calculated for zonal wind or meridional wind. In Figures $2 \mathrm{c}$ and $2 \mathrm{~d}$ the contour interval is 0.1 , and positive and negative values are denoted by solid and dashed lines, respectively.

mentioned in section 1, between the two phenomena. Radiative cooling generally detected at the tops of the low-level clouds [Houze, 1993] could be favorable for the surface Okhotsk high. In section 4 we explore the ability of lowlevel clouds over the Okhotsk Sea to affect the surface Okhotsk high, focusing on July 2003, when the Okhotsk high was most active during the past decade (Figure 2a).

\section{Modeling Low-Level Clouds}

[14] In this section, we simulate the Okhotsk high and low-level clouds over the Okhotsk Sea and investigate the effects of low-level clouds.

\subsection{Case of July 2003}

[15] The model domain is set to be $24^{\circ}-67^{\circ} \mathrm{N}$ and $120^{\circ}-$ $170^{\circ} \mathrm{E}$, which covers the Okhotsk Sea. The lateral boundary condition is set using 6 hourly zonal wind, meridional wind, temperature, specific humidity, and cloud liquid water $(\mathrm{Qc})$ from JRA25 data. These lateral boundary conditions are linearly interpolated in time at every time step. National Oceanic and Atmospheric Administration (NOAA) optimum interpolation sea surface temperature (OISST, daily), with an original resolution of $0.25^{\circ} \times 0.25^{\circ}$, is used as the lower boundary condition over the ocean. We integrate the model from 00:00 UTC on 1 January 2003 for 1 year with the initial condition based on JRA25 data. Note that no nudging or data assimilation is performed in this model, except for 
the boundary conditions. The initial condition of the land process model, BATS, is horizontally uniform; however, the land surface temperature is set to be the atmospheric temperature at the lowest level. Hereafter, this experiment is referred to as the control run (CR).

[16] Figures $3 \mathrm{a}$ and $3 \mathrm{~b}$ show the monthly mean SLP of JRA25 and CR, respectively, in July 2003. The Okhotsk high covers the entire Okhotsk Sea in both CR and JRA25, although its amplitude is slightly larger in CR. The Okhotsk high also tends to be slightly stronger in CR than in JRA25 in other years (not shown). Figures $3 \mathrm{c}$ and $3 \mathrm{~d}$ illustrate vertical-meridional sections of the geopotential height anomaly from the meridional mean (between $35^{\circ}$ and $60^{\circ} \mathrm{N}$ ) at $150^{\circ} \mathrm{E}$ of JRA25 and CR, respectively, in July 2003. A (a)

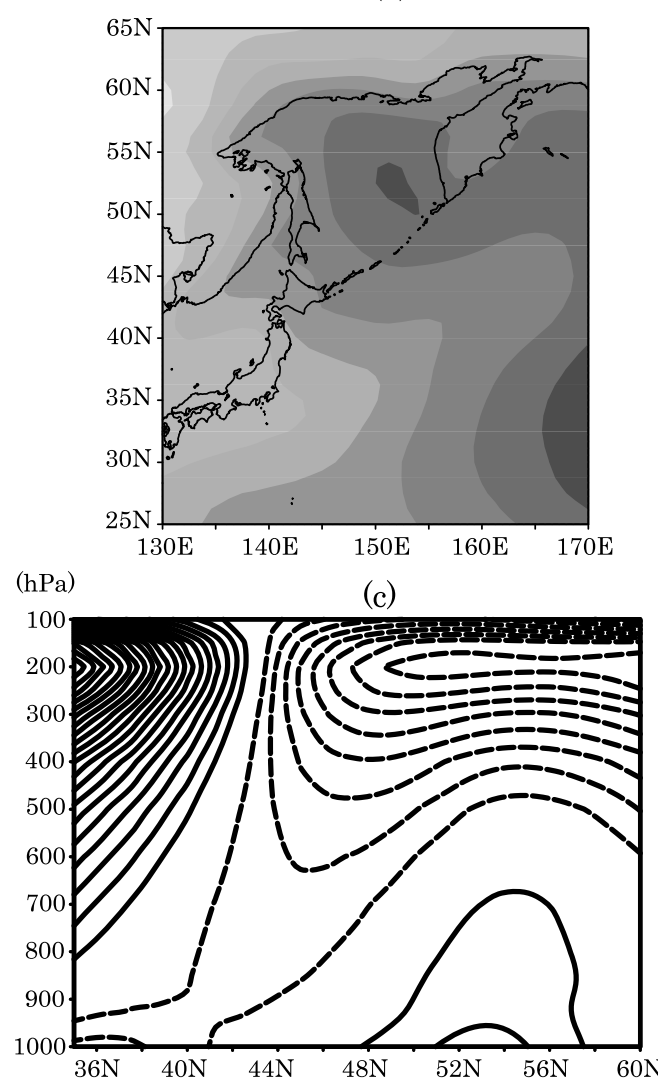

(e)

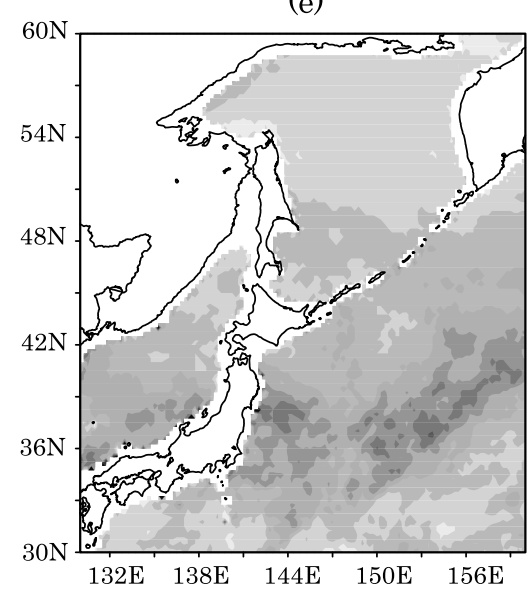

(b)

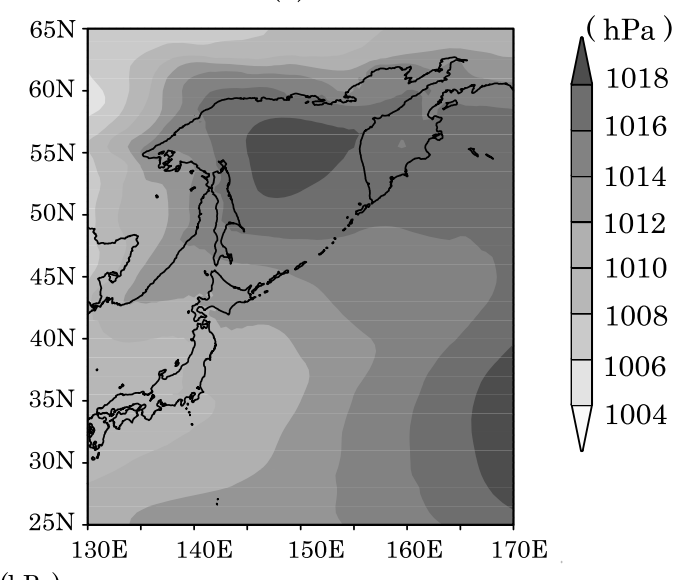

(d)

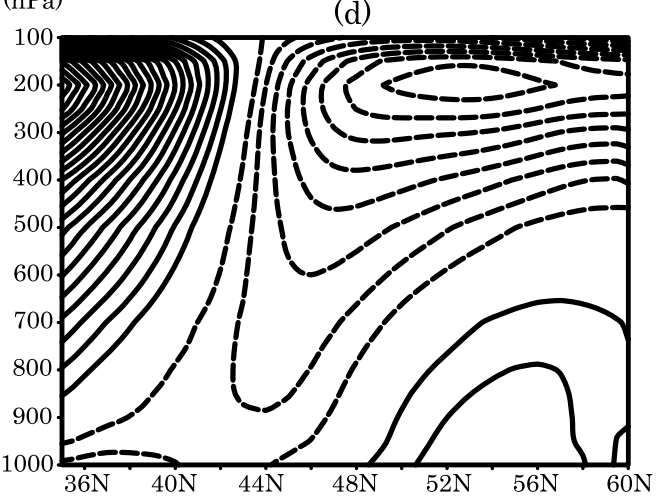

(f)

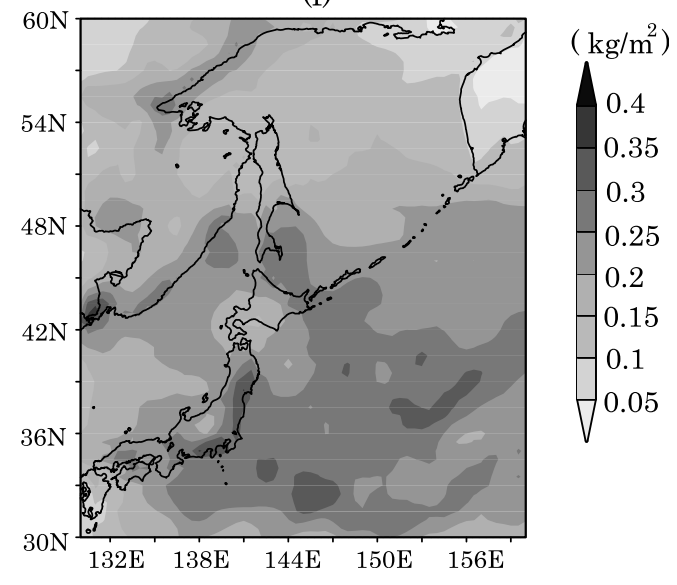

Figure 3. Sea level pressure of (a) JRA25 and (b) CR. Height-latitude sections of the geopotential height anomaly from the meridional average $\left(35^{\circ}-60^{\circ} \mathrm{N}\right)$ at $150^{\circ} \mathrm{E}$ of (c) JRA25 and (d) CR. The contour interval is $10 \mathrm{~m}$, and positive and negative values are denoted by solid and dashed lines, respectively. Also shown is vertically integrated cloud liquid water of (e) SSMI and (f) CR. Figures 3a-3f show monthly mean values in July 2003. (g) Time sequence the area-averaged sea level pressure $\left(45^{\circ}-60^{\circ} \mathrm{N}\right.$ and $140^{\circ}-160^{\circ} \mathrm{E}$ ) in JRA25 (dashed line, 6 hourly) and CR (solid line, daily) in July 2003. 
(g)

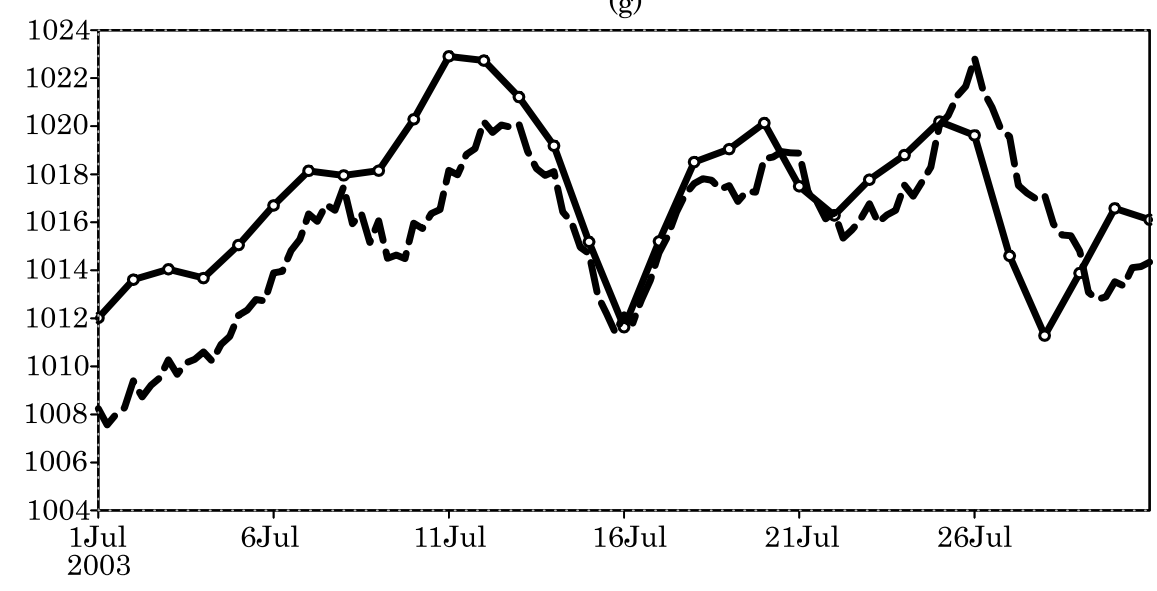

Figure 3. (continued)

positive anomaly is detected between $46^{\circ} \mathrm{N}$ and $58^{\circ} \mathrm{N}$ below $600 \mathrm{hPa}$, indicating that the Okhotsk high is limited to the lower troposphere in both JRA25 and CR. As in the case of SLP, the positive geopotential height anomaly is slightly larger in CR than in JRA25. The July 2003 mean vertically integrated Qc amounts from SSMI and CR are shown in Figures $3 \mathrm{e}$ and $3 \mathrm{f}$, respectively. Although the integrated Qc amount is slightly larger in CR than in SSMI, the distribution is qualitatively similar; the maximum is along the Kuroshio Extension $\left(30^{\circ}-35^{\circ} \mathrm{N}\right.$ and $\left.140^{\circ}-155^{\circ} \mathrm{E}\right)$, and the Qc amount gradually decreases northward, with a slight increase along the northwestern coast of the Okhotsk Sea. Figure $3 \mathrm{~g}$ illustrates the time sequence of the area-averaged SLP $\left(45^{\circ}-60^{\circ} \mathrm{N}\right.$ and $\left.140^{\circ}-160^{\circ} \mathrm{E}\right)$ in CR (solid line, daily) and JRA25 (dashed line, 6 hourly) in July 2003. SLP increases and reaches its maximum on 11 July and varies significantly after 16 July. As can be seen in Figures $3 \mathrm{a}$ and $3 \mathrm{~b}$, the SLP is slightly higher in CR than that in JRA25. Nevertheless, we believe that the model represents the time variation of the Okhotsk high reasonably well because the difference is partly due to the presence (or absence) of the low-level clouds in CR (or JRA25), as is discussed in section 4.2 .

[17] Figures $4 \mathrm{a}$ and $4 \mathrm{~b}$ illustrate the time-height sections of temperature and cloud amount averaged over the Okhotsk Sea in CR. Figure 4a shows a strong inversion layer around $\sigma_{0.96}$, which is a typical feature of a cloud top boundary layer (CBL) [Sedlar and Tjernström, 2009]. The vertical structure of the temperature is relatively stable in the first half of the month (before 16 July) during which the Okhotsk high strengthens before weakening gradually (Figure 4c). In this period, the cloud amount is largest around $\sigma_{0.97}$, above which the inversion layer is located. The low-level clouds reach the surface and are accompanied by a weak drizzle (up to $1-2 \mathrm{~mm} \mathrm{~d}^{-1}$ ) over the Okhotsk Sea (not shown). On the contrary, the inversion layer at the lower levels almost disappears and temperature fluctuates greatly in the second half of the month (after 16 July). Clouds form at higher levels, and low-level cloud amounts become lesser than that seen in the first half of the month. This rise in cloud height and fluctuations in temperature are caused by synoptic-scale cyclones that pass over the Okhotsk Sea in the second half of the month. Although the Okhotsk high occurs in the same period, it is distorted and shifted northward by the synopticscale cyclones (not shown). We, therefore, focus on the first half of the month when both the Okhotsk high and low-level clouds are relatively stable.

[18] Figure $4 \mathrm{~d}$ shows the time-averaged (1-16 July) cloud amount at $\sigma_{0.977}$ in CR, which is estimated from the sum of mixing ratios of cloud liquid water and cloud ice water at this level and thus should not be compared directly with ISCCP low-level cloud data. Most of the Okhotsk Sea is covered by low-level clouds. Two local maxima of low-level cloud amount are located near the eastern part of the Kuril Islands $\left(46^{\circ}-50^{\circ} \mathrm{N}\right.$ and $\left.150^{\circ}-156^{\circ} \mathrm{E}\right)$ and Shelikhov Bay $\left(55^{\circ}-60^{\circ} \mathrm{N}\right.$ and $\left.155^{\circ}-160^{\circ} \mathrm{E}\right)$. In these regions, the oceanic tidal mixing is strong and SST insignificantly lower than that in other regions of the Okhotsk Sea [Nakamura et al., 2000], leading to enhanced low-level cloud occurrence [Tokinaga and Xie, 2009]. CR captures the response to the oceanic tidal cooling effects through the prescribed SST. Conversely, the low-level cloud amount is relatively small north of Sakhalin Island $\left(53^{\circ}-56^{\circ} \mathrm{N}\right.$ and $\left.138^{\circ}-144^{\circ} \mathrm{E}\right)$ and northeast of Hokkaido Island $\left(44^{\circ}-49^{\circ} \mathrm{N}\right.$ and $\left.142^{\circ}-147^{\circ} \mathrm{E}\right)$. The cause of this cloud distribution is investigated in section 5 .

[19] Figures 5a-5d show time-height sections of the areaaveraged heating rates attributed to longwave radiation (LW), large-scale condensation (LSC), turbulent mixing (TM), and shortwave radiation (SW). The cooling caused by LW is strong around $\sigma_{0.97}$ near the cloud top. The absolute value of the LW cooling, whose contribution to the heat budget is the largest, is about $60 \%$ larger than that of LSC heating, which is the second-largest contributor. The strong LW cooling can enhance the Okhotsk high near the surface because colder air is denser and shallower. While the LW cooling rate in the present case is smaller than that attributed to stratus clouds over the North Sea [Nicholls, 1984] and Arctic Ocean [Curry, 1986], it is higher than that caused by stratocumulus clouds over the subtropical ocean [Wang et al., 2004a]. The LSC heating rate is strongest around 

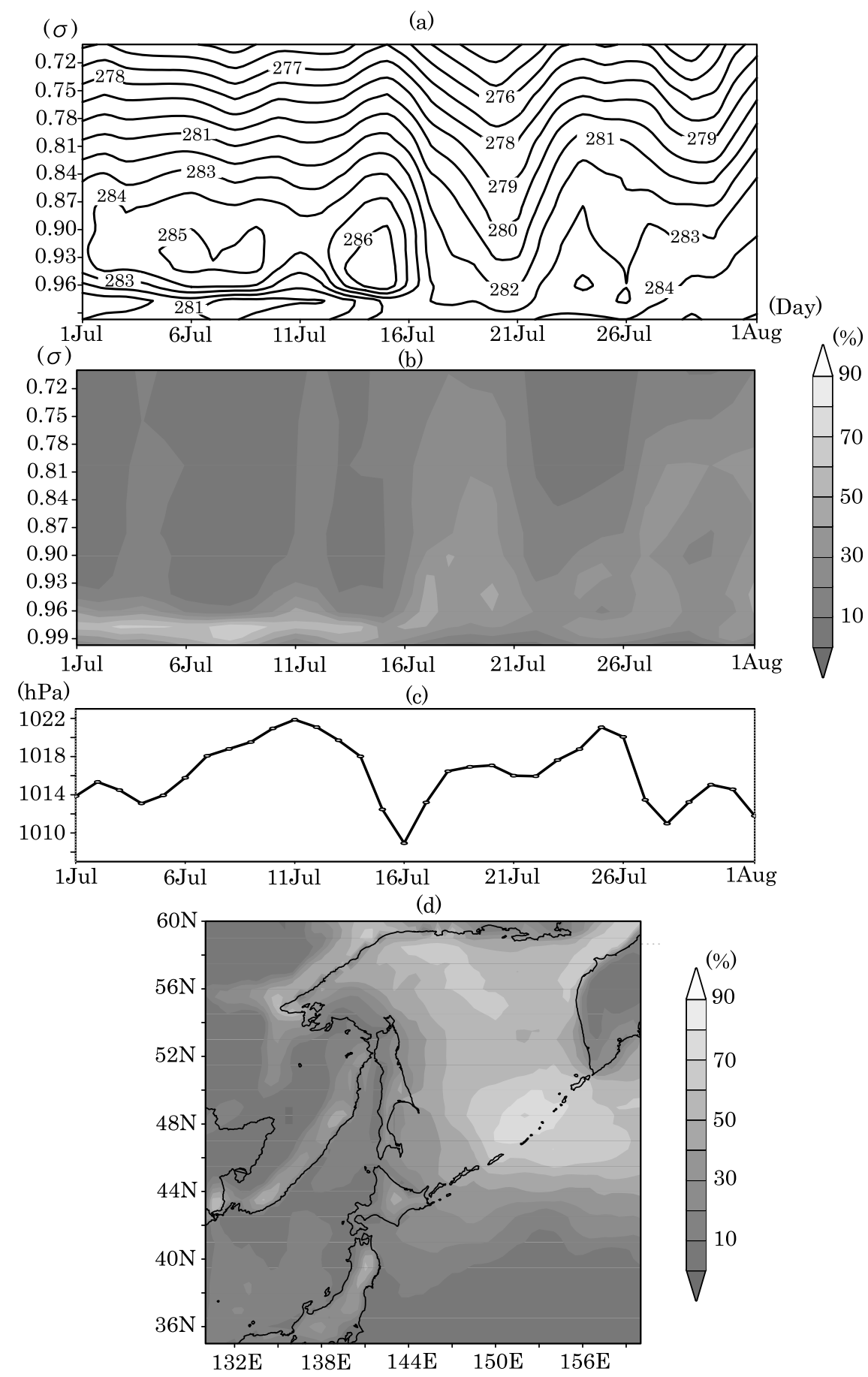

Figure 4. Time-height sections of (a) temperature (K) and (b) cloud amount (percent) averaged over the Okhotsk Sea $\left(45^{\circ}-60^{\circ} \mathrm{N}\right.$ and $\left.140^{\circ}-160^{\circ} \mathrm{E}\right)$ in CR. (c) Time series of the area-averaged sea level pressure in CR. (d) Temporal mean (1-16 July) cloud amount at $\sigma_{0.977}$ in CR.

$\sigma_{0.97}$, and its distribution also coincides approximately with that of cloud amount. In contrast, cumulus convection hardly occurs over the Okhotsk Sea in CR because of the low SST, which reaches only $\sim 283 \mathrm{~K}$. LSC causes cooling near the surface through evaporative cooling of drizzle and cloud water. In this case, this evaporative cooling tends to stabilize the CBL because the cloud base is close to the surface
[Stevens et al., 1998]. This cooling is also favorable for the surface Okhotsk high. TM induces significant heating near the surface and weak cooling above $\sigma_{0.96}$. A part of the latter cooling represents the effects of entrainment, which plays an important role in the formation of stratocumulus clouds [Stevens et al., 2003] and is included in TM. The heating due 
(б)

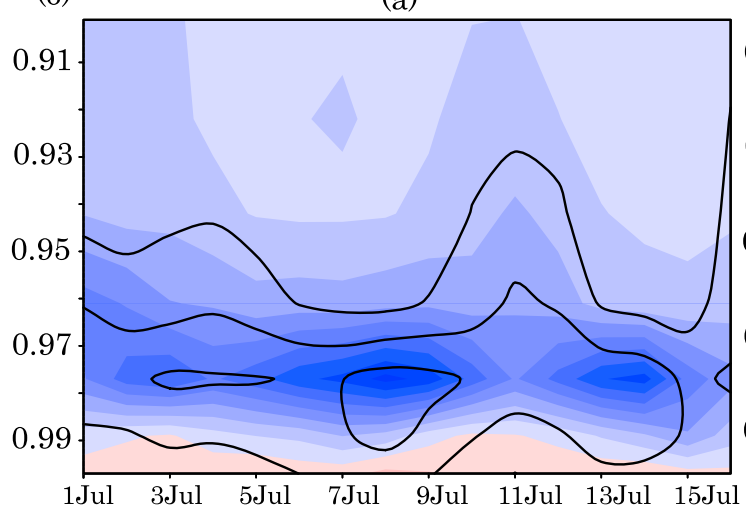

(b)

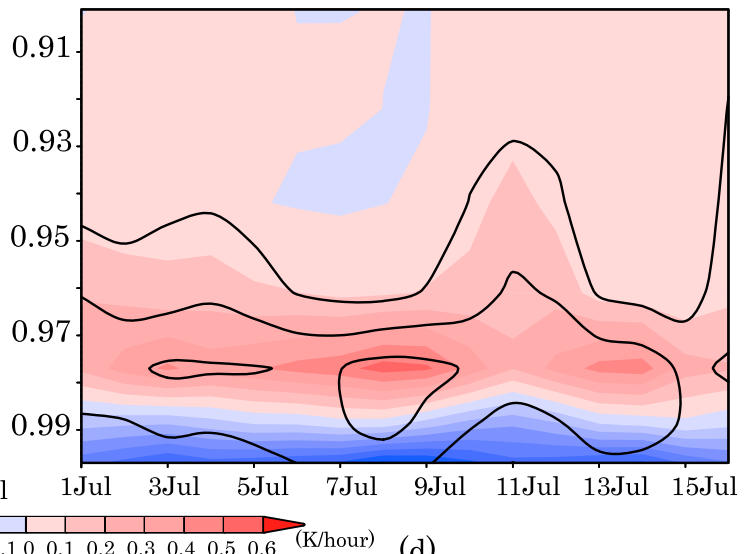

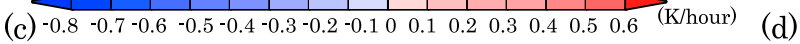
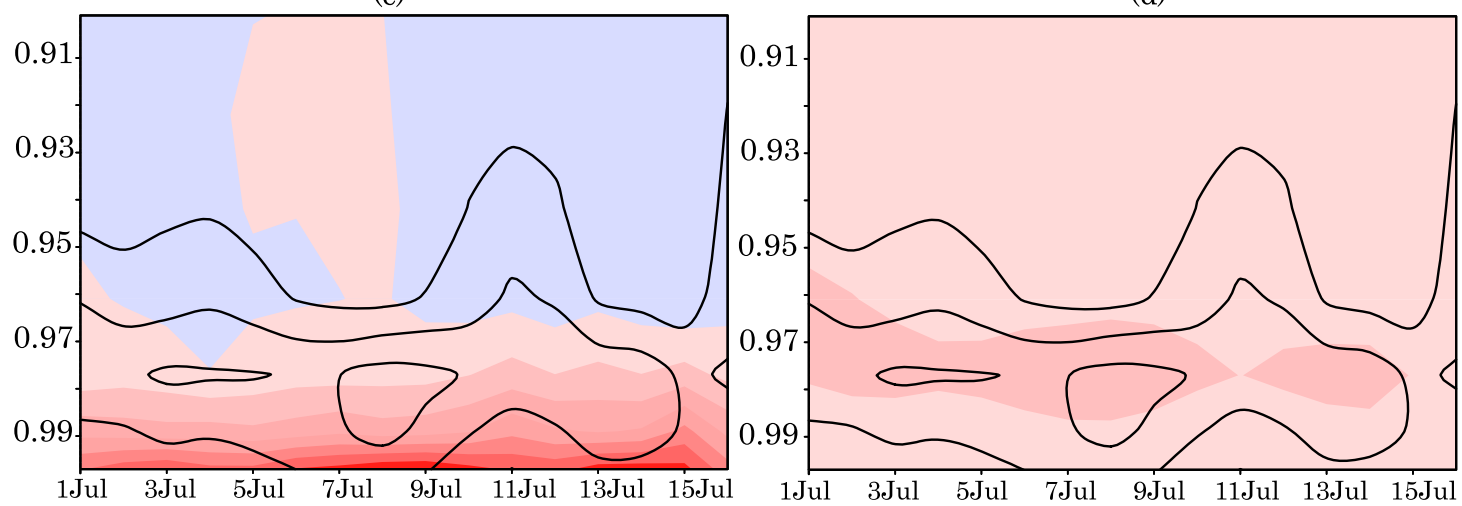

(e)

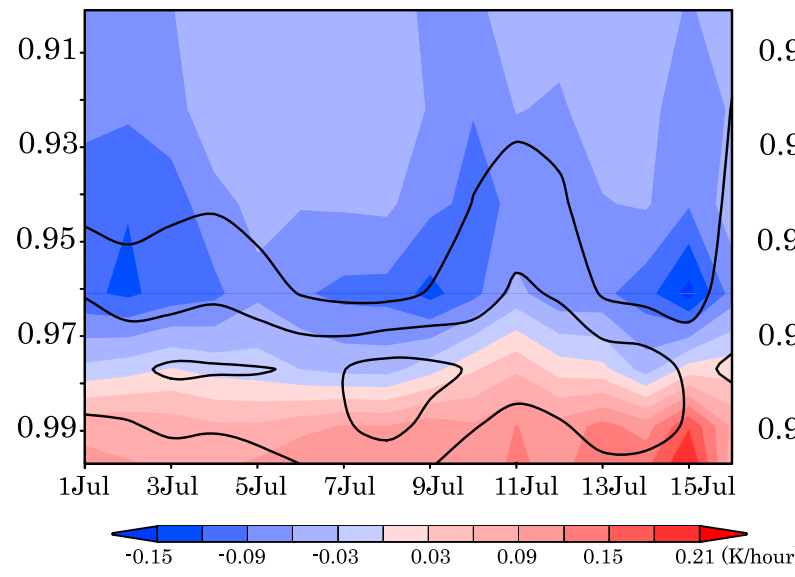

(f)

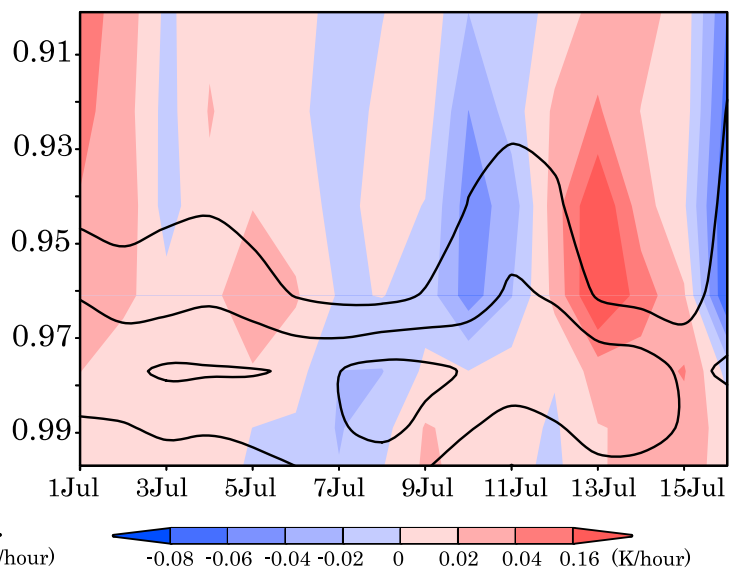

Figure 5. Time-height sections of the area-averaged $\left(45^{\circ}-60^{\circ} \mathrm{N}\right.$ and $\left.140^{\circ}-160^{\circ} \mathrm{E}\right)$ heating rates attributed to (a) longwave radiation, (b) large-scale condensation, (c) turbulent mixing, and (d) shortwave radiation. (e) Sum of heating rates (Figures 5a-5d). (f) Area-averaged temperature tendency in CR. Solid contours represent the area-averaged cloud amount (contour interval is $20 \%$ ).

to $\mathrm{SW}$ is positive; however, its amplitude is significantly smaller than that in LW, LSC, and TM.

[20] Figure 5e shows the sum of the four heating rates. Heating is dominant near the surface, while cooling is strong around $\sigma_{0.96}$. The heating near the surface is caused mainly by TM, which is almost balanced by the cooling due to LSC. The net cooling occurs around $\sigma_{0.96}$ because of the larger absolute value of LW cooling than heating due to LSC and
SW. LW cooling is thus important for maintaining the CBL at a low temperature. Figure $5 \mathrm{f}$ shows the temperature tendency. In CBL, the tendency is significantly smaller than the sum of the four heating rates, and thus the temperature in CBL is almost stable. This is because heating by vertical advection due to subsidence associated with the Okhotsk high almost balances with the sum of the four heating terms due to low-level clouds, although it is less than $15 \%$ of $\mathrm{LW}$ 

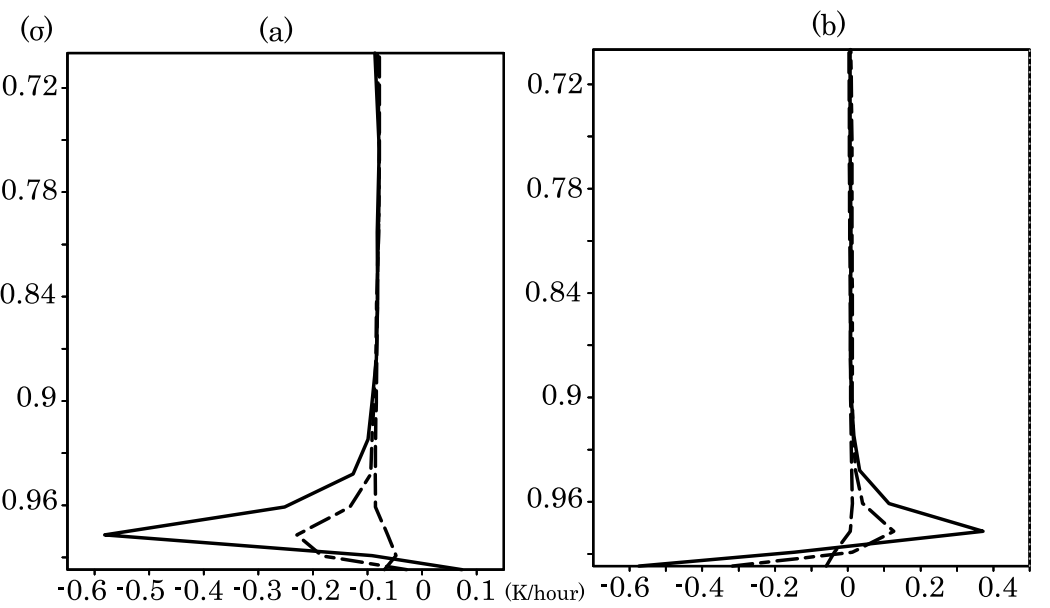

(c)

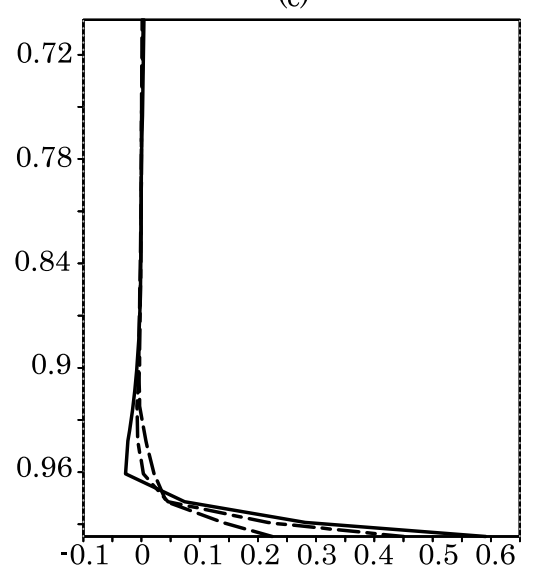

(e)

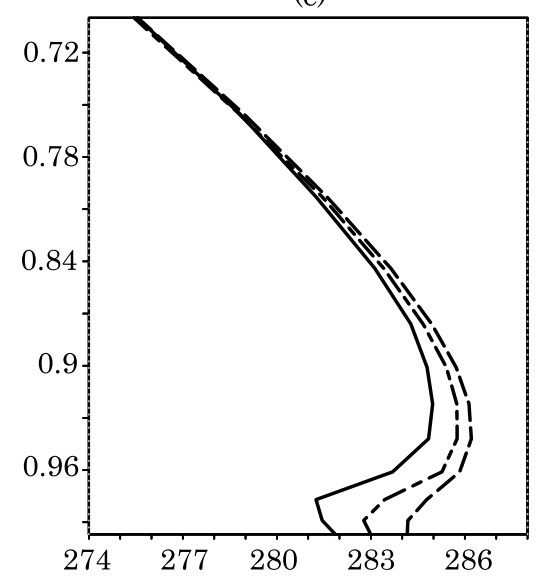

(d)



(f)

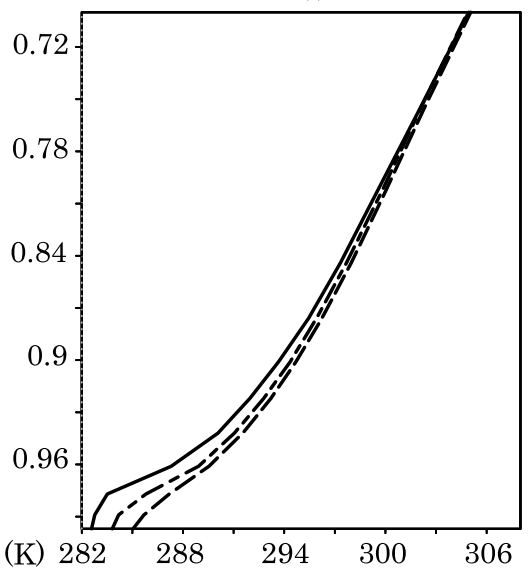

Figure 6. Time (1-16 July) and area-averaged $\left(45^{\circ}-60^{\circ} \mathrm{N}\right.$ and $\left.140^{\circ}-160^{\circ} \mathrm{E}\right)$ vertical profiles of heating rates due to (a) longwave radiation, (b) large-scale condensation, (c) turbulent mixing, and (d) shortwave radiation and those of (e) temperature and (f) virtual potential temperature in CR (solid lines), RCR05 (dot-dashed lines), and RCR01 (dashed lines).

cooling (not shown). Above CBL, temperature tendency is relatively large. At these levels, thermodynamic effects due to low-level clouds are quite small and horizontal advection has a vital role in determining temperature tendency (not shown).

[21] The upward sensible and latent heat fluxes are found in this period with temporal and spatial mean fluxes of 10.8 and $18.7 \mathrm{~W} \mathrm{~m} \mathrm{~m}^{-2}$, respectively, over the Okhotsk Sea. Tachibana et al. [2008] showed positive heat fluxes in the presence of low-level clouds with the shipboard observations. In addition, they suggested that the combination of these upward turbulent fluxes and the cloud top radiation cooling maintains the CBL and effectively forms the lowlevel clouds. 
(a)
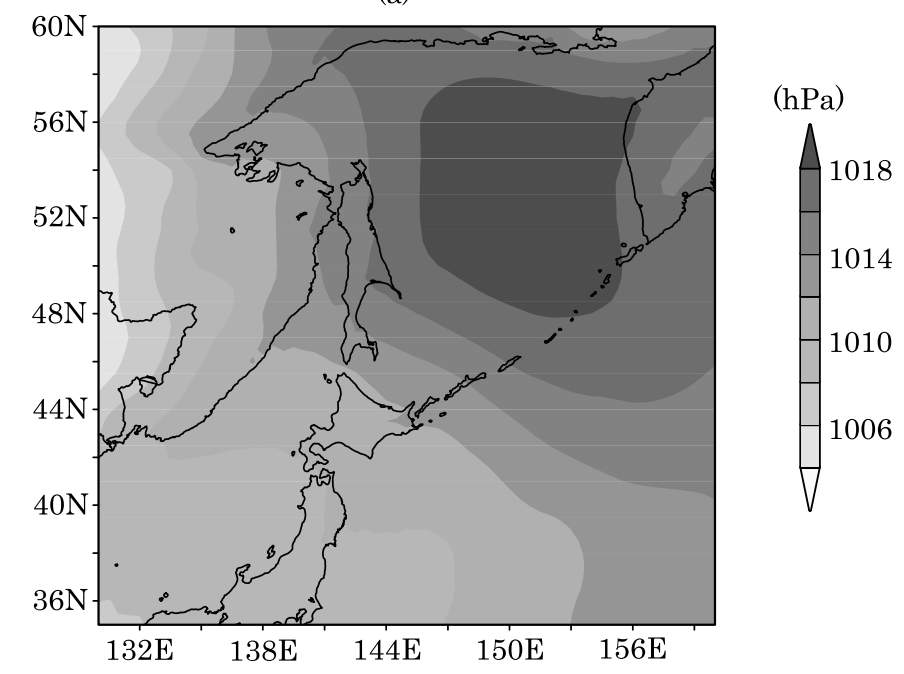

(b)
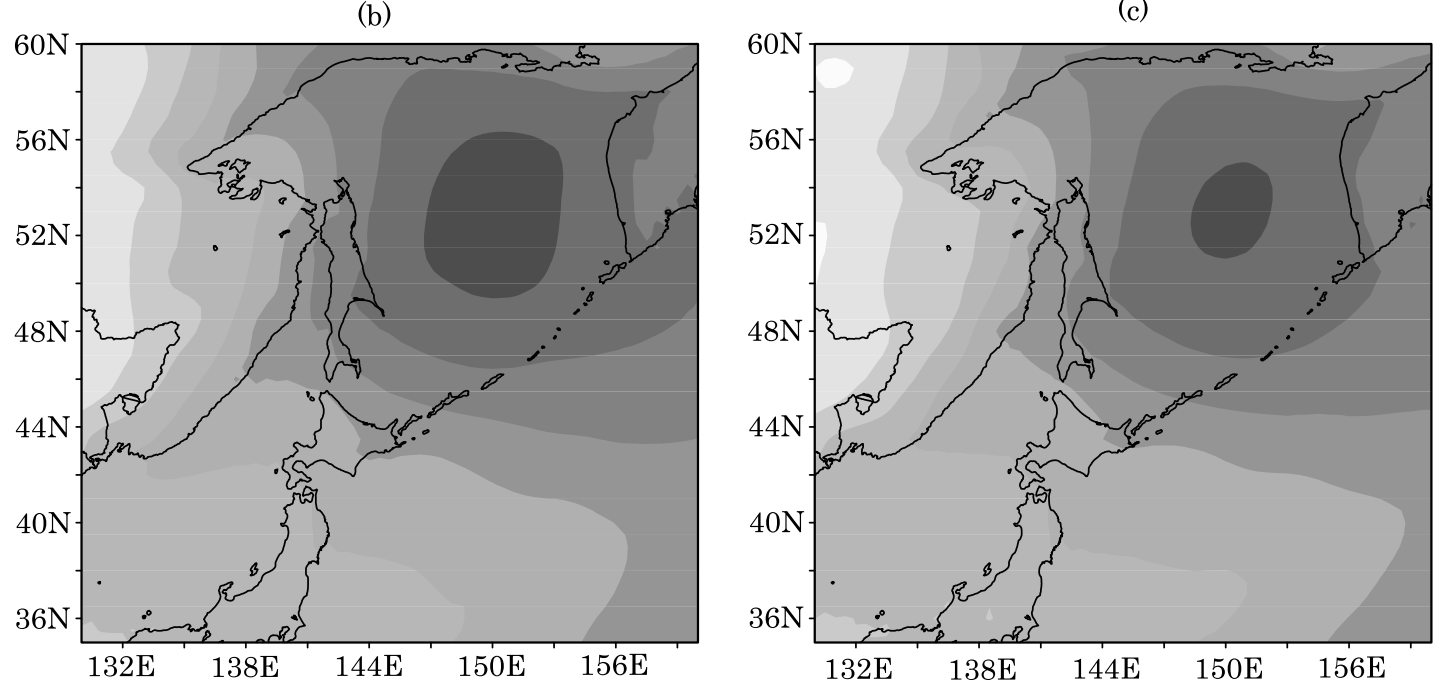

Figure 7. Time-averaged (1-16 July) sea level pressure in (a) CR, (b) RCR05, and (c) RCR01.

\subsection{Thermodynamic Effects of Low-Level Clouds on Cloud Top Boundary Layer}

[22] In section 4.1 we suggested that strong cooling at the tops of low-level clouds is favorable for strengthening the surface Okhotsk high. To investigate this effect, we conduct sensitivity experiments, in which we reduce the effect of cloud amount on radiation, which is achieved by multiplying cloud amount by a constant factor $\gamma(0<\gamma<1)$ when the radiation flux is calculated. This method is almost equivalent to the reduction of heating and cooling effects due to LW and SW associated with clouds. Note that the cloud amount values used in other processes are unchanged by this reduction at the same time step. In addition, this reduction does not affect the estimation of cloud droplet effective radius and cloud optical thickness. Nevertheless, because the values are calculated online, the change in radiation flux results in changes to other variables, which in turn feed back to the radiation. We conduct two sensitivity experiments, in which $\gamma$ is set to be 0.5 and 0.1 , and refer to these experiments as reduced cloud runs (RCRs; RCR05 and RCR01, respectively). Other conditions are the same as those in CR. We explore the radiative effects of low-level clouds by comparing the results of RCRs and CR.

[23] Figures 6a-6d show the time- and area-averaged vertical profiles of heating rate due to $\mathrm{LW}, \mathrm{LSC}, \mathrm{TM}$, and SW in CR (solid line), RCR05 (dot-dashed line), and RCR01 (dashed line). The cooling due to LW weakens significantly in RCR05 and almost disappears in RCR01. The heating due to LSC and TM also diminishes with decreasing $\gamma$, from CR to RCR05 to RCR01. This result implies that Qc is hardly generated, and the upward turbulent heat fluxes are weakened over the Okhotsk Sea in RCRs. As previously described, we reduced only the effects of cloud amount on the radiative process, and Qc is not reduced by this change in the model code. The reduced Qc in RCRs indicates that low-level cloud formation is not effective in RCRs. Although the heating due to SW almost disappears in RCRs around $\sigma_{0.97}$, its relative importance increases near the surface as Qc decreases. Nevertheless, we 
(a)

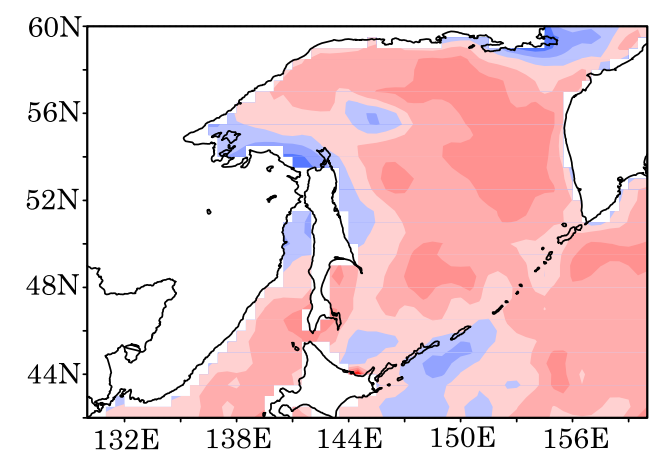

(b)

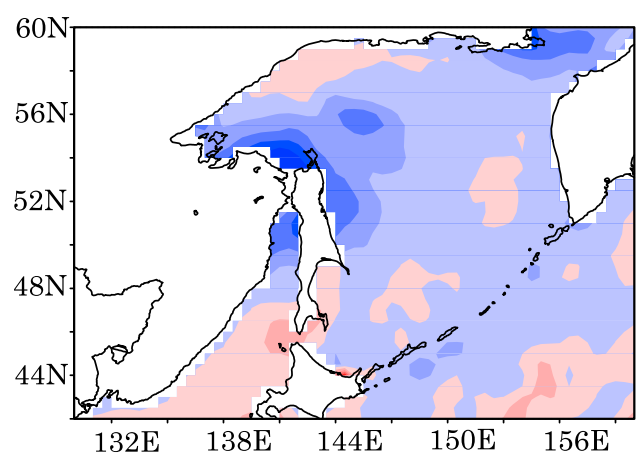

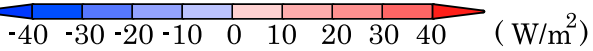

(c)

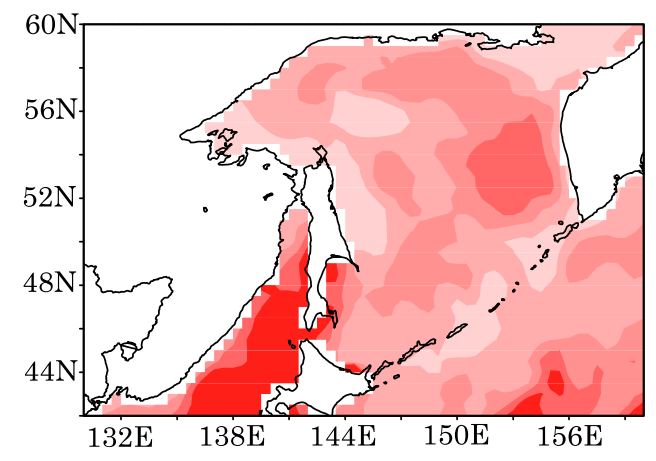

(d)

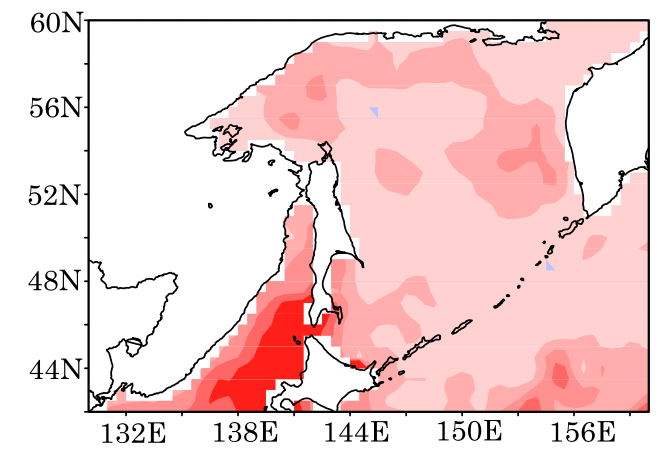

Figure 8. Time-averaged (1-16 July) sensible heat flux in (a) CR and (b) RCR01 and latent heat flux in (c) CR and (d) RCR01. Positive values denote upward sensible and latent heat fluxes.

can neglect the contribution of SW heating in this study because in CR, SW heating is considerably smaller than other heating terms. Figures $6 \mathrm{e}$ and $6 \mathrm{f}$ illustrate the time- and area-averaged vertical profiles of temperature and virtual potential temperature $(\theta \mathrm{v})$, respectively, in CR (solid line), RCR05 (dot-dashed line), and RCR01 (dashed line). In CR, a strong inversion layer associated with the $\mathrm{CBL}$ is detected between $\sigma_{0.977}$ and $\sigma_{0.96}$ (Figure 6e), as described in section 3 . As the cloud amount is reduced in RCRs, the temperature below $\sigma_{0.977}$ increases remarkably. The largest temperature difference between $\mathrm{CR}$ and RCR01 is $\sim 4 \mathrm{~K}$ at $\sigma_{0.977}$. Because the radiative cooling is dominant at this level in $\mathrm{CR}$, the temperature difference is mainly caused by a reduction in radiation effects.

[24] The values of $\theta \mathrm{v}$ in CR (Figure 6f) are approximately constant between the surface and $\sigma_{0.977}$, indicating the development of a mixed boundary layer. With low-level clouds, the CBL is warmed at the surface by turbulent mixing and cooled near the cloud top by LW, as shown in Figure 5e. These heating and cooling cycles tend to maintain the well-developed CBL, resulting in a vertically uniform $\theta \mathrm{v}$. In RCRs, the boundary layer is stabilized, and $\theta \mathrm{v}$ increases vertically because both the cooling by LW and warming by turbulent mixing are reduced.

[25] Figures 7a-7c show the time-averaged horizontal distribution of SLP in CR, RCR05, and RCR01. The Okhotsk high is weakened in RCR05 and diminishes in RCR01 drastically; in particular, the area including SLPs higher than $1018 \mathrm{hPa}$ becomes much smaller around the center of the Okhotsk Sea. In addition, SLP is also reduced over the North Pacific Ocean near the Kamchatka Peninsula. It should be noted that the SLP difference between CR and RCR01 is $\sim 2-3 \mathrm{hPa}$ and is similar to that between $\mathrm{CR}$ and JRA25. As the Okhotsk high weakens, the easterly Yamase winds in northern Japan become weaker and suppressed in RCRs (not shown).

[26] Figures $8 \mathrm{a}$ and $8 \mathrm{~b}$ show the time-mean sea surface sensible heat flux in CR and RCR01, respectively. Although the season is summer, the sensible heat flux in CR is upward over most of the Okhotsk Sea. This upward flux is large in the eastern part of the Okhotsk Sea, where the low-level cloud amount is also large (Figure 4d). In contrast, the sensible heat flux is downward in RCR01 over most of the Okhotsk Sea. This switch in the direction of surface sensible heat flux is attributed to the warmed surface atmosphere owing to suppressed LW cooling in RCR01. Figures 8c and $8 \mathrm{~d}$ show the time-mean sea surface latent heat flux in $\mathrm{CR}$ and RCR01, respectively. Although the direction of the latent heat flux is the same, its amplitude is significantly weaker in RCR01. The sensible and latent heat fluxes in RCR01 are -5.8 and $9.4 \mathrm{~W} \mathrm{~m}^{-2}$, respectively, when averaged over time (1-16 July) and area $\left(45^{\circ}-60^{\circ} \mathrm{N}\right.$ and $140^{\circ}-$ $160 \mathrm{E}^{\circ}$ ). The differences (CR minus RCR01) are 153 and $50 \%$ of the values in CR (see section 4.1).

[27] It should be argued that the stochastic response due to synoptic-scale disturbances is insignificant in the previous 
analysis. In these experiments, the lateral boundary condition largely controls the synoptic and larger-scale atmospheric fields, including the Okhotsk high. In addition, the Okhotsk high persists and synoptic cyclones do not pass over the Okhotsk Sea in the analysis period. Actually, the SLP decrease in RCRs compared with CR is detected every day in the analysis period, which indicates that the response is not stochastic. Moreover, the RCRs show an almost linear response to decreasing $\gamma$, as previously described. We thus consider that the effects of stochastic response are small in the present model setting.

\section{Low-Level Cloud Formation Over the Okhotsk Sea}

[28] To clarify the mechanism of low-level cloud formation over the Okhotsk Sea, we in this section focus on the process through which unsaturated air masses become saturated over the Okhotsk Sea.

\subsection{Less Cloud Formation in the Western Part of the Okhotsk Sea}

[29] The low-level cloud formation is not frequent in the western part of the Okhotsk Sea, particularly to the north of Sakhalin Island and northeast of Hokkaido Island, as shown in Figure 4d. In this section, we examine the reason from an Eulerian perspective. Figure 9a illustrates a time-longitude section of cloud amount and horizontal wind vector at $\sigma_{0.977}$ at $55^{\circ} \mathrm{N}$ near the northern coast of Sakhalin Island, from 1 to 16 July 2003. During this period, the southerly winds due to the Okhotsk high are dominant and particularly strong between $137^{\circ}$ and $144^{\circ} \mathrm{E}$. Low-level clouds do not form when the southerly winds from the lands are relatively strong. In contrast, such cloud formation, seen around 5 and 15 July, tends to correlate with easterly winds blowing from the sea.

[30] Figure $9 \mathrm{~b}$ shows a temperature anomaly from the time average (1-16 July) at $\sigma_{0.977}$ and sea surface sensible heat flux on a section represented in Figure 9a. Positive temperature anomalies are detected most often in the cloudless periods shown in Figure 9a.In these periods, the surface sensible heat flux is downward, indicating that the high temperature in this region is not forced by the underlying SST. Moreover, the time period and area of high temperature coincide approximately with those of strong southerly winds shown in Figure 9a, indicating that these warm air masses are advected by the strong southerly winds from the land, in this case, Sakhalin Island or Siberia. In fact, a large thermal contrast is present between the warm land and the cold surface of the Okhotsk Sea in summer, as shown by Tachibana et al. [2004]. An examination of the CR results reveals that this infrequent cloud formation due to the advection of landoriginated warm air masses also occurs in other coastal regions such as those around the Kamchatka Peninsula and the northern coast of the Okhotsk Sea (not shown).

[31] Figures $9 c$ and $9 d$ are the same as Figures $9 a$ and $9 b$, respectively, but represent $47^{\circ} \mathrm{N}$, to the northeast of Hokkaido Island, where low-level clouds do not occur frequently in Figure 4d. Low-level clouds do not form between $143^{\circ}$ and $149^{\circ} \mathrm{E}$ near 3 and 11 July because, around these 2 days, the warm southerly winds associated with the Okhotsk high are dominant, although the winds are weak on 3 July. These warm air masses are advected from the North Pacific Ocean rather than from land because CR does not resolve the Kuril Islands. In contrast, low-level clouds form around 2 July and between 5 and 9 July, when the winds are weak easterlies and cold air advects from the eastern part of the Okhotsk Sea. After 13 July, low-level clouds do not form, although the winds are strong and dominated by easterlies or northeasterlies, because these strong winds are caused by a synoptic-scale cyclone that brings warm air. Except for the last period, the absence of low-level clouds is associated with warm air advection from outside of the Okhotsk Sea to northeast of Hokkaido Island as in the case of the region to the north of Sakhalin Island. The surface sensible heat flux is negative on 11 July and weakly positive on 3 July when lowlevel clouds are absent and temperature is relatively high, whereas the flux is strongly positive when these clouds are present and temperature is relatively low. This relationship is similar to that in the case north of Sakhalin Island.

[32] Note that SST in the Okhotsk Sea is generally lower than SST in the open North Pacific, because of high latitudes, sea ice melting, and tidal mixing. Accordingly, the winds from the North Pacific usually cause warm air advection. This point differs from stratocumulus cloud formation in the eastern subtropical regions.

\subsection{Forward Trajectory Analysis}

[33] In section 5.1 we suggested that low-level clouds tend not to form when warm air masses are advected to the Okhotsk Sea from outer regions such as the land area or the North Pacific Ocean. However, the warm air masses would be saturated to form stratiform clouds because of the modification by the sea surface fluxes, if they remain over the Okhotsk Sea for a sufficiently long period. We thus track unsaturated air masses originating from the outer regions to examine their modification by the local processes over the Okhotsk Sea.

[34] To track the air masses, we seed passive tracers north of Sakhalin Island $\left(53^{\circ} \mathrm{N}\right.$ and $\left.142^{\circ} \mathrm{E}\right)$ and northeast of Hokkaido Island $\left(46^{\circ} \mathrm{N}\right.$ and $\left.146^{\circ} \mathrm{E}\right)$ at $\sigma_{0.977}$. Tracers are set once per day at 00:00 UTC (09:00 LTC) during 1-15 July. The passive tracers are governed only by the horizontal advection-diffusion equation used in the calculation of $\mathrm{CR}$. The vertical advection and diffusion terms are excluded in the calculation of the passive tracers, because vertical displacements by vertical advection are negligibly small in this period owing to the stable Okhotsk high.

[35] Figure 10 illustrates the hourly trajectories of the center of the tracers for $24 \mathrm{~h}$ north of Sakhalin Island and $36 \mathrm{~h}$ northeast of Hokkaido Island from the onset time of each tracer. We neglect the air masses that are saturated or almost saturated at the onset time and those that reach the land without condensation over the sea, to explore the mechanism by which unsaturated air masses are modified and condense over the Okhotsk Sea. Nine of 30 cases are adopted after this selection, with onset dates of 1,2, 6, 9, 10, 11 , and 14 July north of Sakhalin Island and 3 and 4 July for the northeastern region of Hokkaido Island. All air masses are advected from land or North Pacific by southeasterly or southwesterly winds associated with the Okhotsk high; the direction of zonal winds depends on the position of the Okhotsk high center. The selected days nearly correspond to those without clouds in Figure 9 except for the cloudless 
(a)

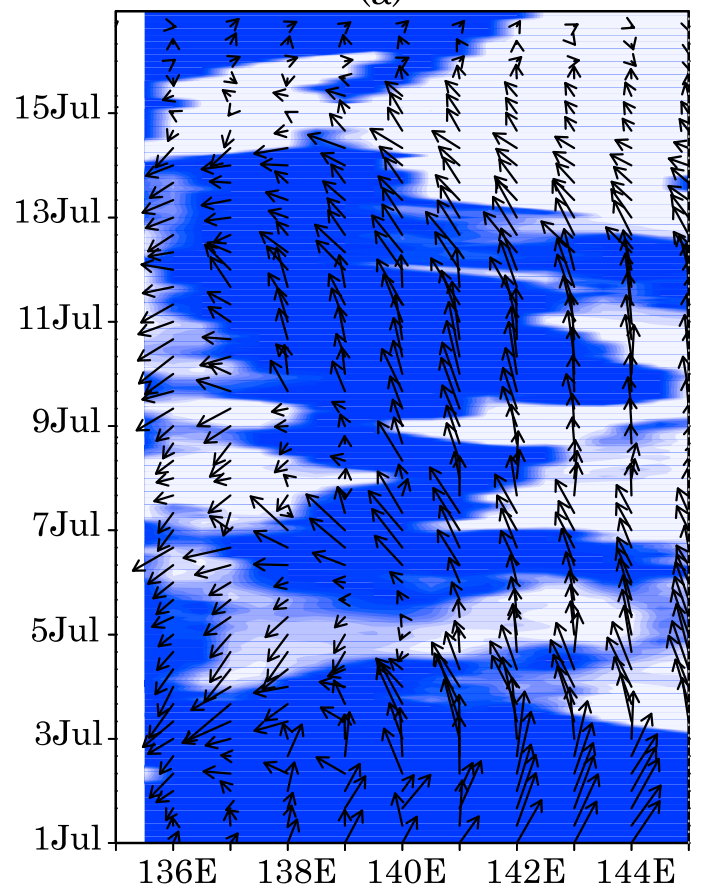

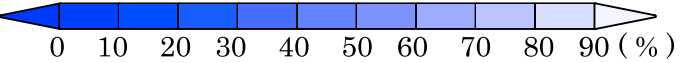

(c) 30

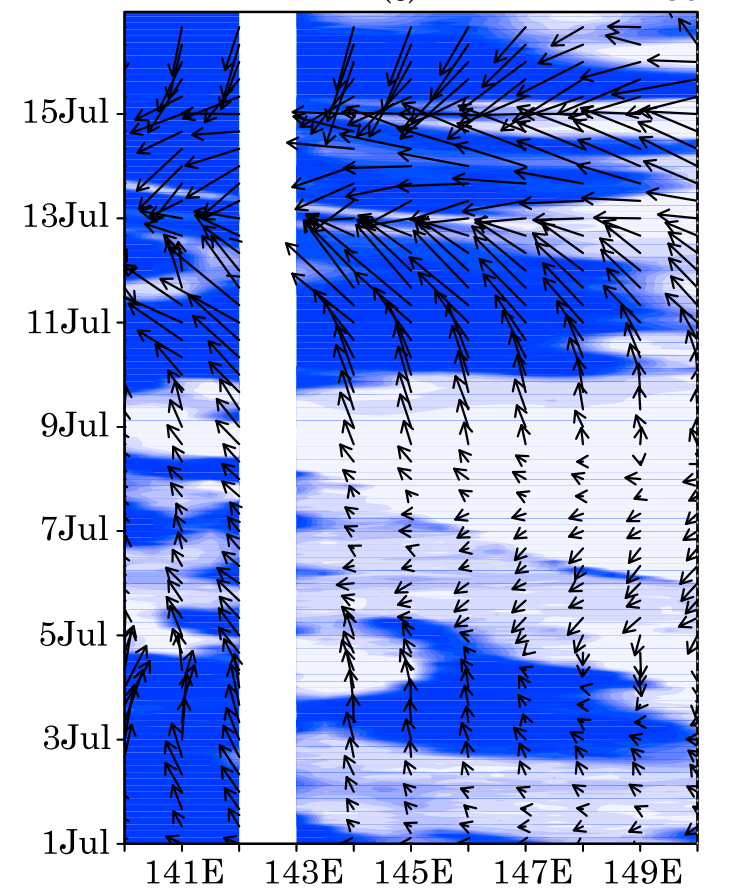

(b)

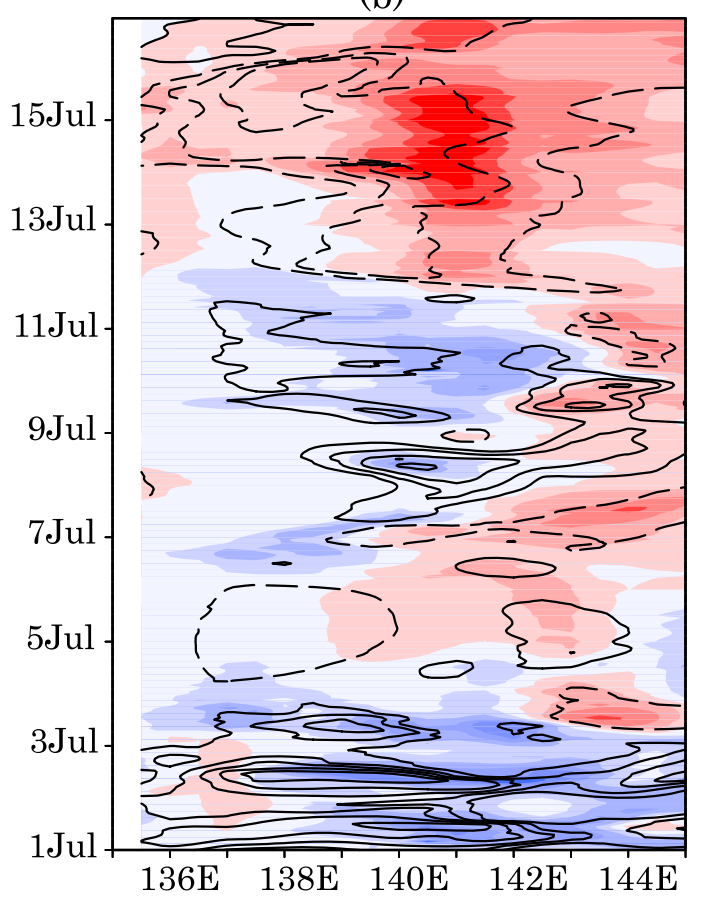

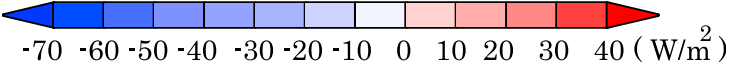

(d)

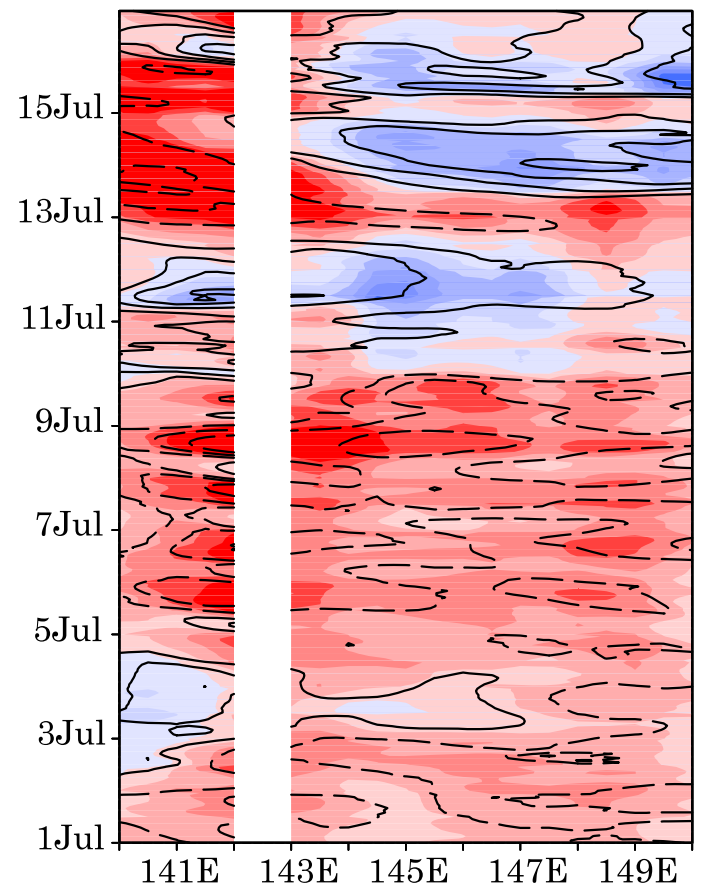

Figure 9. Time-longitude sections of (a) cloud amount (shading) and horizontal wind (vectors) at $\sigma_{0.977}$ and (b) temperature anomaly from the time average (1-16 July) at $\sigma_{0.977}$ (contours) and surface sensible heat flux (shading) at $55^{\circ} \mathrm{N}$ in CR. (c and d) Same as Figures $9 \mathrm{a}$ and $9 \mathrm{~b}$ but at $47^{\circ} \mathrm{N}$. The contour intervals are $2 \mathrm{~K}$ in Figure $9 \mathrm{~b}$ and $1 \mathrm{~K}$ in Figure $9 \mathrm{~d}$. 


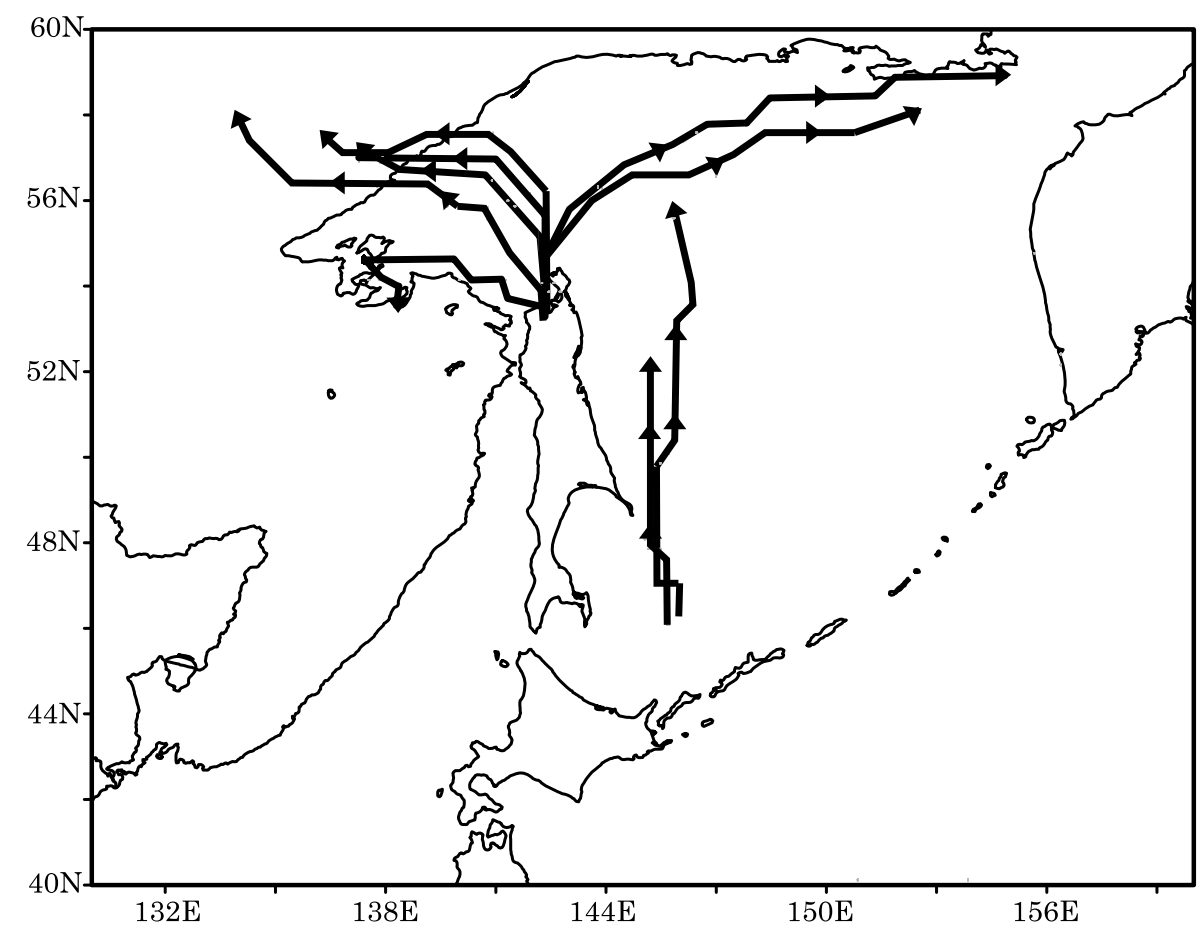

Figure 10. Forward trajectories of passive tracers used in Lagrangian analysis.

days influenced by a synoptic-scale cyclone, with slight differences arising from differences in latitudes. Therefore, these samples are representative for cloud formation in these regions.

[36] Figure 11 shows time sequences of cloud amount superposed with heating rate due to $\mathrm{LW}$, heating (cooling) rate due to condensation of water vapor (evaporation of raindrop and cloud water), temperature at $\sigma_{0.977}$, SST, relative humidity at $\sigma_{0.977}$, and surface heat fluxes for the air masses seeded north of Sakhalin Island. Each variable shown is the ensemble average of the seven cases, whereby the average is obtained for the same elapsed time from the onset. Until hour 9 after the onset, the cloud amount is less than $20 \%$, although the cloud formation occurs slowly. The cloud amount increases dramatically, particularly around $\sigma_{0.977}$ after hour 12 , and reaches more than $80 \%$ after hour 18. As the cloud amount increases, the cooling due to LW becomes substantially strong around hour 12 and persists afterward.

[37] The temperature at $\sigma_{0.977}$ gradually decreases by $\sim 1 \mathrm{~K}$ from hour 0 to hour 9 but decreases sharply by $\sim 3 \mathrm{~K}$ from hour 9 to hour 14 and remains low afterward (Figure 11c). On the contrary, the SST change is relatively small, although it increases by $1.0-1.5 \mathrm{~K}$ throughout the trajectory process. The relative humidity at $\sigma_{0.977}$ shows a temporal change opposite that of the temperature (Figure 11d). The relative humidity is below $90 \%$ at the onset time and increases gradually until hour 9 . The value then rapidly increases between hour 9 and hour 12, finally exceeding 100\% thereafter. Although the specific humidity also increases in the CBL, its contribution to the increase in relative humidity is negligible compared with that of temperature (not shown).

[38] The surface heat fluxes present interesting variations. The latent heat flux is positive (upward) during the entire period, indicating that air masses gain moisture over the Okhotsk Sea. The sensible heat flux is negative (downward) at the onset time and cools the air masses-gradually because the land-originated air masses are warmer than the underlying SST. Once the air masses reach the dew point temperature, low-level clouds begin to form, around hour 10, after which time, the cloud formation is enhanced and radiative cooling becomes strong. Although heating by condensation and cooling by evaporation act to stabilize $\mathrm{CBL}$ (Figure 11b), the enhanced radiative cooling and upward sensible heat flux tend to destabilize the CBL; a balance between these effects maintains the CBL, as indicated in section 4.1. The importance of the radiative cooling for maintaining the $\mathrm{CBL}$ is similar to that in other regions [Nicholls, 1984; Rogers and Koračin, 1992]. These temporal variations of variables along the trajectory are detected for each individual tracer (not shown).

[39] Figure 12 provides the same information as that represented in Figure 11, except for the region to the northeast of Hokkaido Island. The variables shown are averaged for two air masses seeded on 3 and 4 July. At the onset time, low-level clouds do not form below $\sigma_{0.977}$ but occur above $\sigma_{0.96}$. These clouds do not form locally but are advected from the North Pacific Ocean by southerly winds. Except for this region, clouds do not occur between $\sigma_{0.96}$ and $\sigma_{0.94}$ elsewhere over the Okhotsk Sea on 3 and 4 July (not shown). The generation time for low-level clouds is longer at $\sigma_{0.977}$ in this case than that of Sakhalin. The cloud formation around $\sigma_{0.977}$ begins at around hour 24, when the cloud amount above $\sigma_{0.96}$ decreases. The cooling due to LW associated with the initial cloud is also detected above $\sigma_{0.96}$ from the onset to hour 24. The dominant height of low-level clouds and radiation cooling after hour 24 is relatively higher than those in the case of Sakhalin. In the present case, the cooling due to evaporation is detected around $\sigma_{0.977}$ 

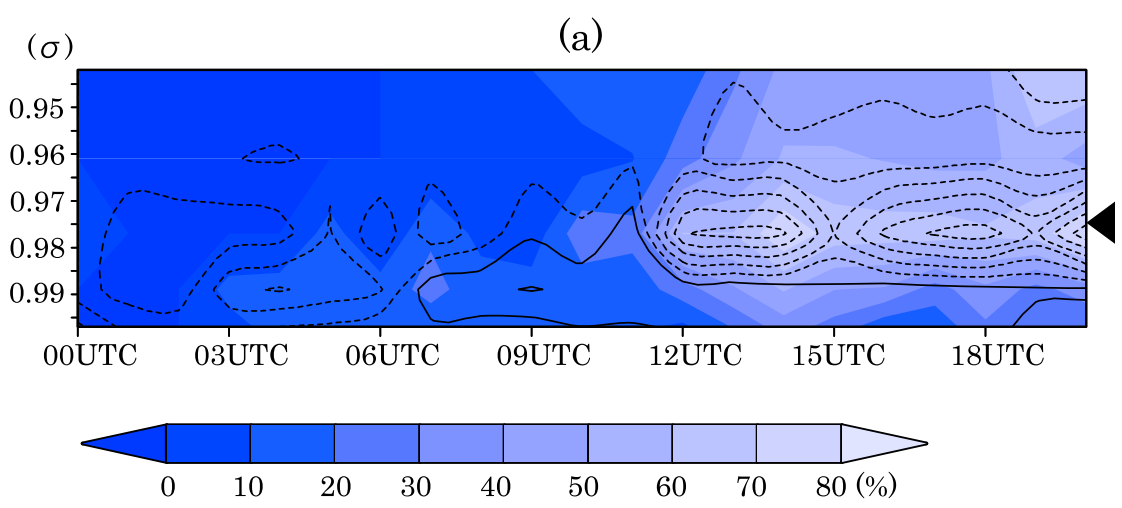

$(\sigma)$

(b)

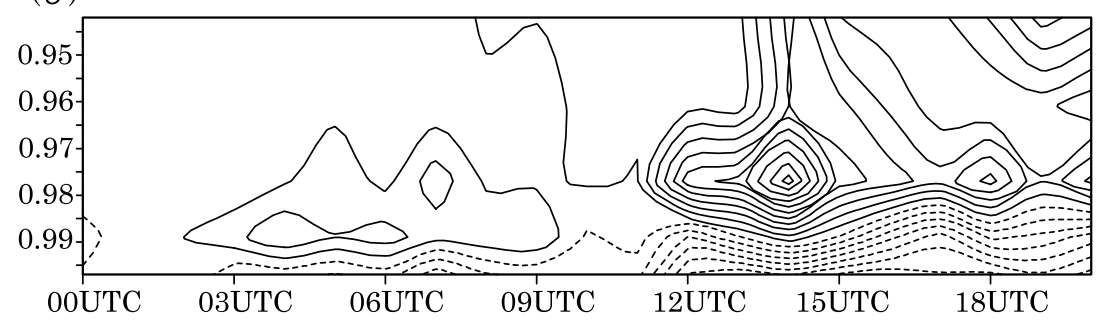

(c)

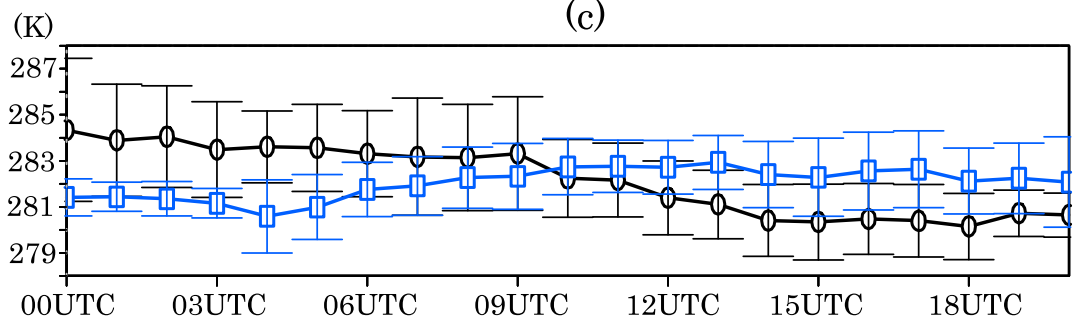

(\%)

(d)

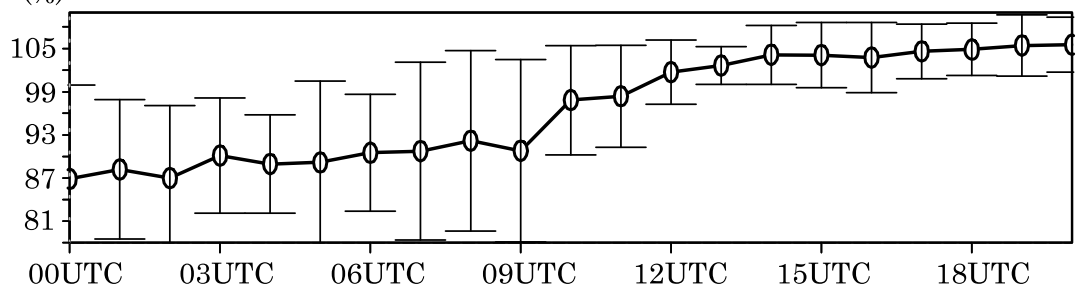

$\left(\mathrm{W} / \mathrm{m}^{-2}\right)$

(e)

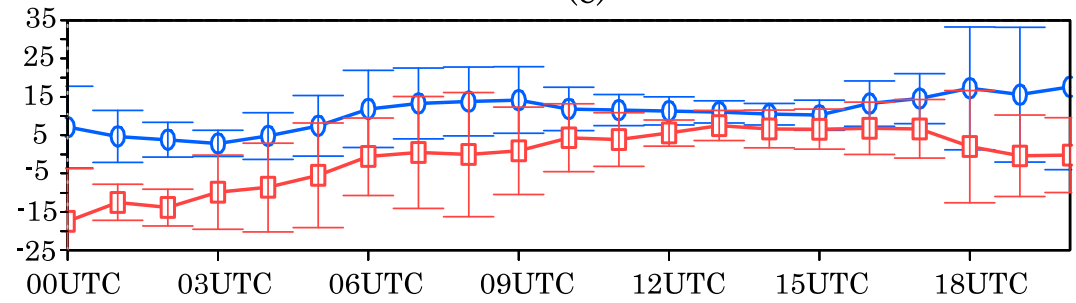

Figure 11. Lagrangian time sequences of ensemble-averaged (a) cloud amount (shading) and heating rate due to longwave radiation, (b) heating rate due to large-scale condensation, (c) temperature at $\sigma_{0.977}$ (black line) and SST (blue line), (d) relative humidity at $\sigma_{0.977}$, and (e) latent (blue line) and sensible (red line) heat fluxes for the air mass seeded north of Sakhalin Island. Error bars denote one standard deviation around the ensemble average. In Figures $11 \mathrm{a}$ and $11 \mathrm{~b}$ the contour interval is $2 \times 10^{-5} \mathrm{~K} \mathrm{~s}^{-1}$, and heating and cooling are represented by solid and dotted lines, respectively. The solid triangle in Figure 11a denotes the level at which the passive tracers are initially seeded. 


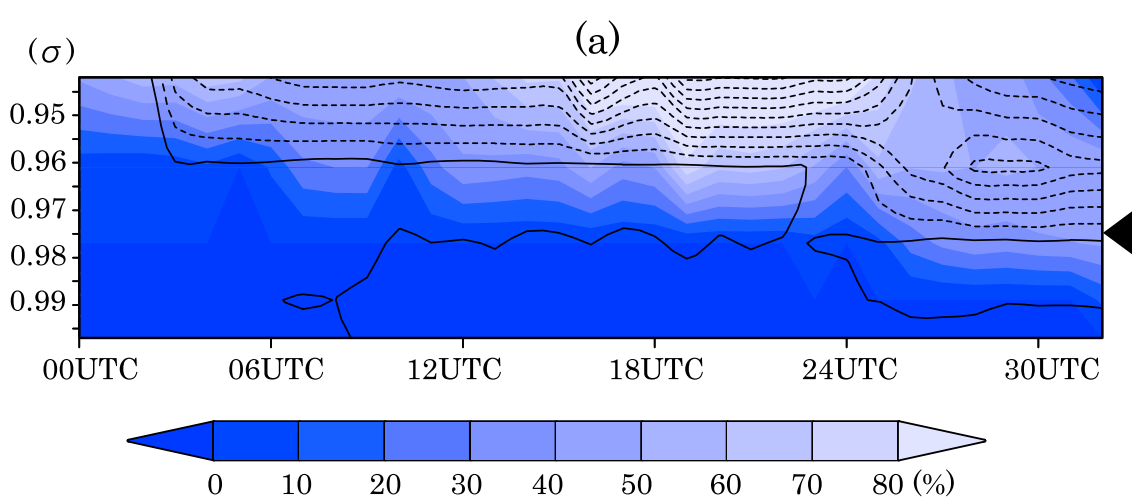

$(\sigma)$

(b)

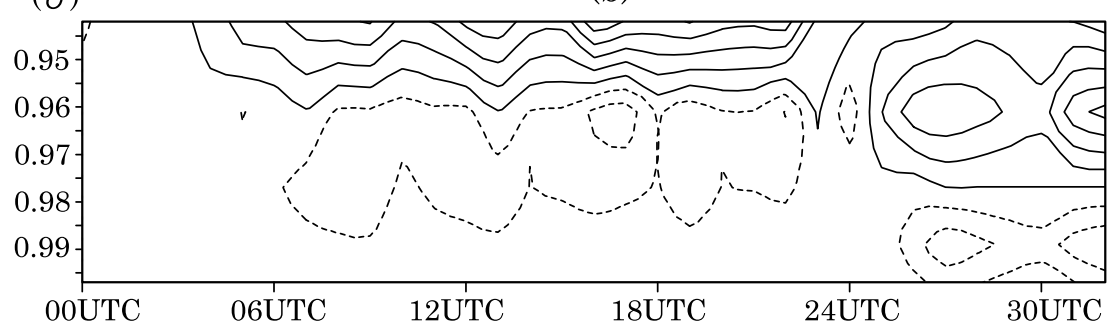

(K)

(c)

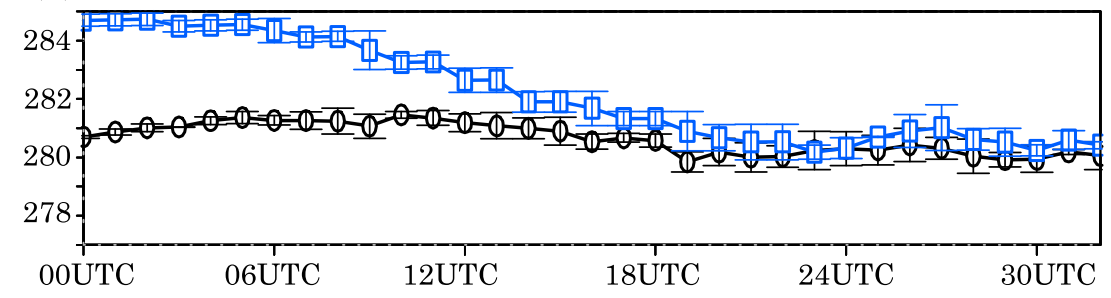

(\%)

(d)

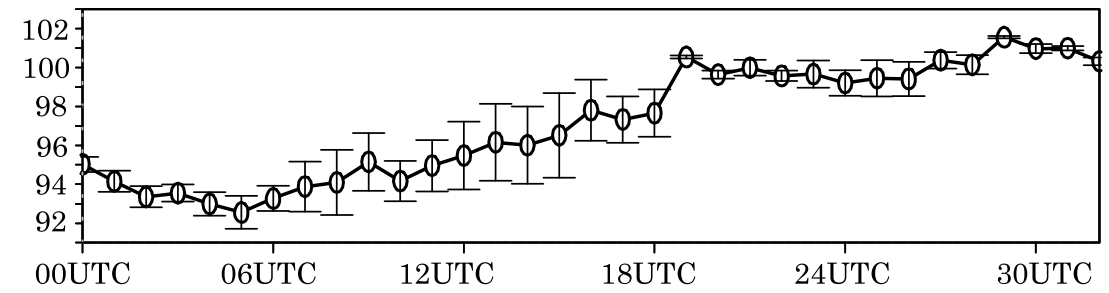

$\left(\mathrm{W} / \mathrm{m}^{-2}\right)$

(e)

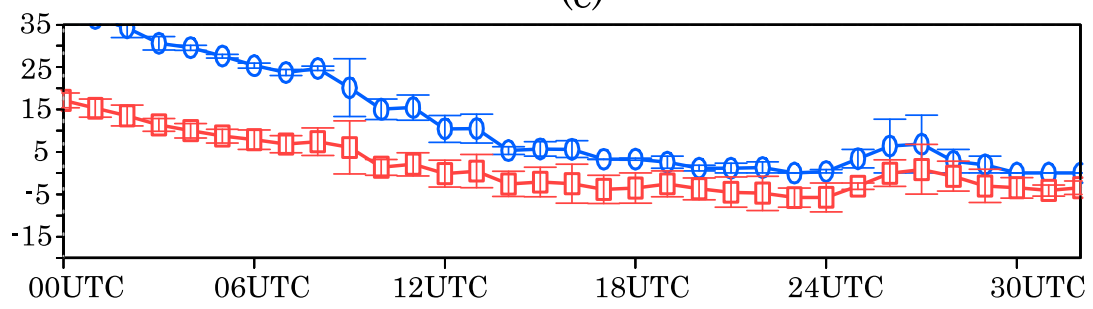

Figure 12. Same as Figure 11 but for the case to the northeast of the Hokkaido Island.

between hour 6 and hour 22. This evaporation is associated with cloud liquid water and drizzle attributed to the initial cloud above $\sigma_{0.96}$. SST is significantly higher than air temperature at the onset time and then decreases. Since the air masses move northward (Figure 10) and the prescribed SST is based on daily means, the above change in SST arises mainly from the meridional rather than temporal change in SST. Conversely, the temperature is nearly constant from the onset time to hour 6 and decreases gradually thereafter, although the decrease in temperature is less rapid than that for Sakhalin Island. Relative humidity is nearly constant between hour 0 and 6 , after which time the value tends 
to increase slowly and reaches almost $100 \%$ after hours 19 to 20 .

[40] The latent heat flux is positive as in the case of Sakhalin Island; however, the sensible heat flux is positive from hour 0 to hour 12 owing to the high SST in this area, which differs from the flux in the case of Sakhalin Island. During this period, the temperature in the lower atmosphere is nearly constant because of the balance between the cooling due to evaporation of drizzle and cloud liquid water and the upward sensible heat flux. Between hours 12 and 24, the sensible heat flux becomes slightly negative because the air masses reach the lower SST region in the north; afterward, the sensible heat flux becomes slightly positive again until hour 29. The time of the change in direction of the sensible heat flux coincides approximately with that of the formation of low-level clouds around $\sigma_{0.977}$. This change in direction of sensible heat flux is similar to that in the case north of Sakhalin Island, although the period of cloud formation is longer in this case.

[41] The Eulerian perspective reveals that low-level clouds do not form around the regions in which warm and unsaturated air masses are advected from outside of the Okhotsk Sea. The forward trajectory analysis suggests that the warm and unsaturated air masses become saturated through cooling and moistening by sea surface fluxes, forming the lowlevel clouds over the Okhotsk Sea. Once formed, the lowlevel clouds are maintained by radiative cooling and upward sensible heat flux.

\section{Summary and Discussion}

[42] In this study, we have investigated the effects of lowlevel clouds on the Okhotsk high and the cloud formation process over the Okhotsk Sea in summer using reanalysis and observational data sets and a regional climate model. The statistical analysis of the reanalysis and satellite data sets reveals that the low-level cloud amount is positively correlated with the OKH index over the Okhotsk Sea.

[43] The model reproduced both the Okhotsk high and the low-level clouds over the Okhotsk Sea in the CR. When the Okhotsk high was relatively stable, 1-16 July 2003, lowlevel clouds formed along with a strong inversion layer around $\sigma_{0.977}$. The heat budget analysis revealed that the cooling due to longwave radiation was dominant at the tops of the low-level clouds. Large-scale condensation occurred mostly around the low-level clouds, causing heating and providing cloud liquid water. Near the surface, turbulent mixing caused strong heating, which was largely compensated by the cooling due to the evaporation of drizzle and the cloud liquid water. The net heating by these three terms was negative around $\sigma_{0.977}$ and positive near the surface, which destabilized the CBL and stimulated the turbulent mixing within the CBL. In addition, the vertical advection due to subsidence associated with the Okhotsk high balances with the net cooling around CBL top. We conclude that CBL over the Okhotsk Sea is kept in a low-temperature state by thermodynamic effects of low-level clouds and the subsidence due to the Okhotsk high.

[44] Sensitivity experiments with reduced cloud radiation effects demonstrated that the surface Okhotsk high became weaker in RCRs than in CR. The temperature in RCR01 below $\sigma_{0.977}$ increased by approximately a maximum of $4 \mathrm{~K}$.
Both the low-level clouds and the heating due to large-scale condensation disappeared in RCR01. These results can be attributed mainly to the warming due to the suppression of radiative cooling in RCR01. While a mixing layer developed up to $\sigma_{0.977}$ in $\mathrm{CR}$, the boundary layers were stabilized in RCRs. The warming in the lower levels by the reduction in radiative cooling resulted in a change in the direction of the sensible heat flux from upward to downward and a reduction in the upward latent heat flux. This result implies that radiative cooling maintains the upward heat flux by cooling the CBL. The upward latent heat flux supplied water vapor to the $\mathrm{CBL}$, leading to condensation at low levels by radiative cooling at the tops of the low-level clouds. Without LW cooling at the cloud top, the atmospheric boundary layer tended to reach a different warm steady state, in which no clouds formed and a mixed layer did not develop as in RCR01. Wang et al. [2005] have shown that radiative cooling and evaporation of cloud water and drizzle contribute to cooling and strengthen the subtropical high over the southeast Pacific. In addition, evaporative cooling occurred near the surface. Although this near-surface evaporative cooling and heating due to condensation around $\sigma_{0.977}$ are favorable for stabilizing a CBL [Stevens et al., 1998], the upward sensible heat flux and cooling due to LW at cloud top tend to destabilize a CBL. We suggest that these heating/ cooling patterns associated with low-level clouds maintain the CBL and reinforce the surface Okhotsk high because the temperature in the $\mathrm{CBL}$ was lower than that simulated under clear-sky conditions in RCRs. The importance of radiative cooling in cloud maintenance is consistent with previous studies on other regions [Klein and Hartmann, 1993; Lilly, 1968; Stevens, 2005].

[45] The Eulerian perspective analysis of cloud formation revealed that low-level clouds tend to be absent and the sensible heat flux is negative when horizontal winds, such as those originating from land or from the North Pacific Ocean, blow from outside the Okhotsk Sea. The forward trajectory analysis of such unsaturated air masses helps understand the cloud formation process over the Okhotsk Sea. To the north of Sakhalin Island, the warm and unsaturated air masses became cooler and saturated because of the negative sensible and positive latent heat fluxes. Although both fluxes are favorable for condensation in the $\mathrm{CBL}$, the negative sensible heat flux was a more effective condition for achieving saturation. After low-level cloud formation, radiative cooling became sufficient for effective cooling of the CBL, and the positive latent heat flux was enhanced so as to replenish the CBL with water lost by precipitation (not shown). It is noteworthy that the direction of the sensible heat flux changed from downward to upward during this cloud formation. To the northeast of Hokkaido Island, although the initial, unsaturated air masses were colder than the sea surface, the air temperature became higher than SST as the air masses moved northward. Then, cloud formation occurred in a manner similar to that shown in the case of Sakhalin Island, with a similar switch in flux direction. We also suggest that oceanic cooling is important for low-level cloud formation, which is consistent with the results of Tokinaga and Xie [2009], although their study focused on the local cooling effects of SST.

[46] Although the effects of entrainment at the tops of lowlevel clouds were small in our model, this process plays an 
important role in the development of stratocumulus clouds in the subtropics, as concluded by Stevens et al. [2003]. This difference in the significance of entrainment is due partly to vertical resolution and the infrequent occurrence of cumulus convection.

[47] The importance of sensible heat flux and radiative cooling on cloud formation indicates the possible occurrence of air-sea interaction via low-level clouds over the Okhotsk Sea. The low SST enhances low-level cloud formation near the surface through positive sensible heat flux, while the low-level clouds cool the sea surface through radiative cooling. This theory has not been applied to subtropical regions, where marine stratocumulus clouds often occur. Such an interaction may be unique to low SSTs and may occur in other cool oceanic regions such as the Arctic Ocean and the Bering Sea. Moreover, the Okhotsk Sea is a region of seasonal sea ice, and the heat budget in the oceanic mixed layer would affect the sea ice distribution. Our results indicate a drastic change in summertime sensible heat flux depending on whether low-level clouds are present or not. This change in sensible heat flux may modify the heat storage in the Okhotsk Sea and consequently affect the sea ice distribution in the following winter. Inversely, if the sea ice distribution in the previous winter affects the SST in summer, it would also affect low-level cloud formation. Future studies will investigate the effects of lowlevel clouds in summer air-sea interaction over the Okhotsk Sea, as well as that in winter, using an atmosphere-ocean coupled model.

[48] Acknowledgments. The authors are grateful to three anonymous reviewers whose comments contributed to refining the content and presentation of this article. The authors would thank H. Nakamura of the University of Tokyo and Y. Tachibana of Mie University for their helpful discussions and comments. Moreover, the authors express their gratitude to K. Soma of University of Yamanashi for his technical guidance in conducting the experiments using iRAM. This study was supported by the Grant for Joint Research Program of the Institute of Low Temperature Science, Hokkaido University, and by the 2009 collaborative research program, Information Initiative Center, Hokkaido University, Sapporo, Japan. Y. Wang was partly supported by NOAA grant NA07OAR4310257 and DOE/RCGM program grant ER64840.

\section{References}

Chou, M. D., M. J. Suarez, C. H. Ho, M. M. H. Yan, and K. T. Lee (1998), Parameterizations for cloud overlapping and shortwave single-scattering properties for use in general circulation and cloud ensemble models, $J$. Clim., 11, 202-214, doi:10.1175/1520-0442(1998)011<0202:PFCOAS $>2$ $0 . \mathrm{CO} ; 2$.

Curry, J. A. (1986), Interactions among turbulence, radiation and microphysics in Arctic stratus clouds, J. Atmos. Sci., 43, 90-106, doi:10.1175/15200469(1986)043<0090:IATRAM>2.0.CO;2.

Detering, H. W., and D. Etling (1985), Application of the E- $-\varepsilon$ turbulence model to the atmospheric boundary layer, Boundary Layer Meteorol., 33, 113-133, doi:10.1007/BF00123386.

Dickinson, R. E., A. Henderson-Sellers, and P. J. Kennedy (1993), Biosphere-Atmosphere Transfer Scheme (BATS) version 1 as coupled to the NCAR Community Climate Model, Tech. Note NCAR/TN387 + STR, 72 pp., Natl. Cent. for Atmos. Res., Boulder, Colo.

Dong, X., and G. G. Mace (2003), Arctic stratus cloud properties and radiative forcing derived from ground-based data collected at Barrow, Alaska, J. Clim., 16, 445-461, doi:10.1175/1520-0442(2003)016<0445: ASCPAR $>2.0 . \mathrm{CO} ; 2$.

Edwards, J. M., and A. Slingo (1996), Studies with a flexible new radiation code. Part 1. Choosing a configuration for a large-scale model, $Q$. J. R. Meteorol. Soc., 122, 689-719, doi:10.1002/qj.49712253107.

Gao, S. H., H. Lin, B. Shen, and G. Fu (2007), A heavy sea fog event over the Yellow Sea in March 2005: Analysis and numerical modeling, $A d v$. Atmos. Sci., 24, 65-81, doi:10.1007/s00376-007-0065-2.
Houze, R. A. (1993), Cloud Dynamics, Academic, San Diego, Calif.

Kato, K. (1985), Heat budget in the atmosphere and the variation of the air temperature in the lower layer over the Okhotsk Sea (a case study during the Baiu Season in 1979) [in Japanese], Tenki, 32, 33-41.

Klein, S. A., and D. L. Hartmann (1993), The seasonal cycle of low stratiform clouds, J. Clim., 6, 1587-1606, doi:10.1175/1520-0442(1993) 006<1587:TSCOLS $>2.0$.CO;2.

Kodama, Y. M. (1997), Air mass transformation of the Yamase air-flow in the summer of 1993, J. Meteorol. Soc. Jpn., 75, 737-751.

Kodama, Y. M., Y. Tomita, and S. Asano (2009), Air mass transformation along trajectories of airflow and its relation to vertical structures of the maritime atmosphere and clouds in Yamase events, J. Meteorol. Soc. Jpn., 87, 665-685, doi:10.2151/jmsj.87.665.

Koračin, D., J. A. Businger, C. E. Dorman, and J. M. Lewis (2005), Formation, evolution, and dissipation of coastal sea fog, Boundary Layer Meteorol., 117, 447-478, doi:10.1007/s10546-005-2772-5.

Lewis, J. M., D. Koračin, and K. T. Redmond (2004), Sea fog research in the United Kingdom and United States: A historical essay including outlook, Bull. Am. Meteorol. Soc., 85, 395-408, doi:10.1175/BAMS-85-3395.

Lilly, D. K. (1968), Models of cloud topped mixed layers under a strong inversion, Q. J. R. Meteorol. Soc., 94, 292-309, doi:10.1002/qj. 49709440106

Lin, W. Y., M. H. Zhang, and N. G. Loeb (2009), Seasonal variation of the physical properties of marine boundary layer clouds off the California Coast, J. Clim., 22, 2624-2638, doi:10.1175/2008JCLI2478.1.

Nagasawa, R., T. Iwasaki, S. Asano, K. Saito, and H. Okamoto (2006), Resolution dependence of nonhydrostatic models in simulating the formation and evolution of low-level clouds during a "Yamase" event, J. Meteorol. Soc. Jpn., 84, 969-987, doi:10.2151/jmsj.84.969.

Nakamura, H., and T. Fukamachi (2004), Evolution and dynamics of summertime blocking over the blocking the associated surface Okhotsk high, Q. J. R. Meteorol. Soc., 130, 1213-1233, doi:10.1256/qj.03.101.

Nakamura, T., T. Awaji, T. Hatayama, K. Akimoto, T. Takizawa, T. Kono, Y. Kawasaki, and M. Fukasawa (2000), The generation of large-amplitude unsteady lee waves by subinertial K1 tidal flow: A possible vertical mixing mechanism in the Kuril Straits, J. Phys. Oceanogr., 30, 1601-1621, doi: $10.1175 / 1520-0485(2000) 030<1601$ :TGOLAU $>2.0 . C O ; 2$.

Nicholls, S. (1984), The dynamics of stratocumulus: Aircraft observations and comparison with a mixed layer model, $Q$. J. R. Meteorol. Soc., 110, 783-820, doi:10.1002/qj.49711046603.

Ninomiya, K., and H. Mizuno (1985), Anomalous cold spell in summer over northeastern Japan caused by northeasterly wind from polar maritime air mass. Part 2: Structure of the northeasterly flow from polar maritime air mass, J. Meteorol. Soc. Jpn., 63, 859-871.

Nordeng, T. E. (1995), Extended versions of the convective parameterization scheme at ECMWF and their impact on the mean and transient activity of the model in the tropics, Res. Dep. Tech. Memo. 206, 41 pp., Eur. Cent. for Medium-Range Weather Forecasts, Reading, U. K.

Norris, J. R., and S. A. Klein (2000), Low cloud type over the ocean from surface observations. Part III: Relationship to vertical motion and the regional surface synoptic environment, J. Clim., 13, 245-256.

Norris, J. R., Y. Zhang, and J. M. Wallace (1998), Role of low clouds in summertime atmosphere-ocean interaction over the North Pacific, J. Clim., 11, 2482-2490, doi:10.1175/1520-0442(1998)011<2482:ROLCIS >2.0.CO;2.

Ogi, M., Y. Tachimaba, and K. Yamazaki (2004), The connectivity of the winter North Atlantic Oscillation (NAO) and the summer Okhotsk high, J. Meteorol. Soc. Jpn., 82, 905-913, doi:10.2151/jmsj.2004.905.

Onogi, K., et al. (2007), The JRA-25 Reanalysis, J. Meteorol. Soc. Jpn., 85, 369-432, doi:10.2151/jmsj.85.369.

Paluch, R. I., and D. H. Lenschow (1991), Stratiform cloud formation in the marine boundary layer, J. Atmos. Sci., 48, 2141-2158, doi:10.1175/15200469(1991)048<2141:SCFITM>2.0.CO;2.

Rogers, D. P., and D. Koračin (1992), Radiative transfer and turbulence in the cloud-topped marine atmospheric boundary layer, J. Atmos. Sci., 49, 1473-1486, doi:10.1175/1520-0469(1992)049<1473:RTATIT>2.0.CO;2.

Sedlar, J., and M. Tjernström (2009), Stratiform cloud-inversion characterization during the Arctic melt season, Boundary Layer Meteorol., 132, 455-474, doi:10.1007/s10546-009-9407-1.

Stevens, B. (2005), Atmospheric moist convection, Annu. Rev. Earth Planet. Sci., 33, 605-643, doi:10.1146/annurev.earth.33.092203.122658. Stevens, B., W. R. Cotton, G. Feingold, and C.-H. Moeng (1998), Largeeddy simulation of strongly precipitating, shallow, stratocumulus-topped boundary layers, J. Atmos. Sci., 55, 3616-3638, doi:10.1175/1520-0469 (1998)055<3616:LESOSP $>2.0 . C O ; 2$.

Stevens, B., et al. (2003), Dynamics and chemistry of marine stratocumulusDYCOM-2, Bull. Am. Meteorol. Soc., 84, 579-593, doi:10.1175/BAMS84-5-579. 
Tachibana, Y., T. Iwamoto, M. Ogi, and Y. Watanabe (2004), Abnormal meridional temperature gradient and its relation to the Okhotsk high, $J$ Meteorol. Soc. Jpn., 82, 1399-1415, doi:10.2151/jmsj.2004.1399.

Tachibana, Y., K. Iwamoto, H. Ogawa, M. Shiohara, K. Takeuchi, and M. Wakatsuchi (2008), Observational study on atmospheric and oceanic boundary-layer structures accompanying the Okhotsk anticyclone under fog and non-fog conditions, J. Meteorol. Soc. Jpn., 86, 753-771, doi: $10.2151 /$ jmsj.86.753.

Takai, H., H. Kawamura, and O. Isoguchi (2006), Characteristics of the Yamase winds over oceans around Japan observed by the scatterometer-derived ocean surface vector winds, J. Meteorol. Soc. Jpn., 84, 365-373, doi:10.2151/jmsj.84.365.

Tiedtke, M. (1989), A comprehensive mass flux scheme for cumulus parameterization in large-scale models, Mon. Weather Rev., 117, 1779-1800, doi:10.1175/1520-0493(1989)117<1779:ACMFSF>2.0.CO;2.

Tokinaga, H., and S.-P. Xie (2009), Ocean tidal cooling effect on summer sea fog over the Okhotsk Sea, J. Geophys. Res., 114, D14102, doi:10.1029/2008JD011477.

Wang, B.-H. (1985), Distributions and variations of sea fog in the world, in Sea Fog, pp. 51-90, China Ocean Press, Beijing.

Wang, Y. (2001), An explicit simulation of tropical cyclones with a triply nested movable Mesh primitive equation model: TCM3. Part I: Model description and control experiment, Mon. Weather Rev., 129, 1370-1394, doi:10.1175/1520-0493(2001)129<1370:AESOTC >2.0.CO;2.

Wang, Y., O. L. Sen, and B. Wang (2003), A highly resolved regional climate model (IPRC-RegCM) and its simulation of the 1998 severe precipitation event over China, J. Clim., 16, 1721-1738.

Wang, Y., S.-P. Xie, and H. Xu (2004a), Regional model simulations of marine boundary-layer clouds over the southeast Pacific off South
America. Part I: Control experiment, Mon. Weather Rev., 132, 274-296, doi:10.1175/1520-0493(2004)132<0274:RMSOMB>2.0.CO;2.

Wang, Y., H. Xu, and S.-P. Xie (2004b), Regional model simulations of marine boundary-layer clouds over the southeast Pacific off South America. Part II: Sensitivity experiments, Mon. Weather Rev., 132, 2650-2668, doi:10.1175/MWR2812.1.

Wang, Y., S.-P. Xie, B. Wang, and H. Xu (2005), Large-scale atmospheric forcing by southeast Pacific boundary-layer clouds: A regional model study, J. Clim., 18, 934-951, doi:10.1175/JCLI3302.1.

Wang, Y., L. Zhou, and K. Hamilton (2007), Effect of convective entrainment/detrainment on simulation of tropical precipitation diurnal cycle, Mon. Weather Rev., 135, 567-585, doi:10.1175/MWR3308.1.

Zhang, S., S.-P. Xie, Q.-Y. Liu, Y.-Q. Yang, X.-G. Wang, and Z.-P. Ren (2009), Seasonal variations of Yellow Sea fog: Observations and mechanisms, J. Clim., 22, 6758-6772, doi:10.1175/2009JCLI2806.1.

Zuidema, P., D. Painemal, S. de Szoeke, and C. Fairall (2009), Stratocumulus cloud-top height estimation and their climatic implications, J. Clim., 22, 4652-4666, doi:10.1175/2009JCLI2708.1.

S. Koseki, Temasek Laboratories, Nanyang Technological University, 9th Storey, BorderX Block, Research Techno Plaza, 50 Nanyang Dr., Singapore 637553, Singapore. (skoseki@ntu.edu.sg)

H. Mitsudera and T. Nakamura, Pan Okhotsk Research Center, Institute of Low Temperature Science, Hokkaido University, Kita-19, Nishi-8, Kita-ku, Sapporo, Hokkaido 060-9819, Japan.

Y. Wang, International Pacific Research Center, School of Ocean and Earth Science and Technology, University of Hawaii at Mānoa, 1680 East-West Rd., POST Building, Rm. 409G, Honolulu, HI 96822, USA. 